\title{
Manduca Contactin Regulates Amyloid Precursor Protein-Dependent Neuronal Migration
}

\author{
Jenna M. Ramaker, ${ }^{1,2,3}$ Tracy L. Swanson, ${ }^{1}$ and $₫$ Philip F. Copenhaver ${ }^{1,3}$ \\ ${ }^{1}$ Department of Cell, Developmental and Cancer Biology, ${ }^{2}$ Department of Pathology, and ${ }^{3}$ Neuroscience Graduate Program, Oregon Health \& Science \\ University, Portland, Oregon 97239
}

\begin{abstract}
Amyloid precursor protein (APP) was originally identified as the source of $\beta$-amyloid peptides that accumulate in Alzheimer's disease (AD), but it also has been implicated in the control of multiple aspects of neuronal motility. APP belongs to an evolutionarily conserved family of transmembrane proteins that can interact with a variety of adapter and signaling molecules. Recently, we showed that both APP and its insect ortholog [APPL (APP-Like)] directly bind the heterotrimeric G-protein Go $\alpha$, supporting the model that APP can function as an unconventional Go $\alpha$-coupled receptor. We also adapted a well characterized assay of neuronal migration in the hawkmoth, Manduca sexta, to show that APPL-Go $\alpha$ signaling restricts ectopic growth within the developing nervous system, analogous to the role postulated for APP family proteins in controlling migration within the mammalian cortex. Using this assay, we have now identified Manduca Contactin (MsContactin) as an endogenous ligand for APPL, consistent with previous work showing that Contactins interact with APP family proteins in other systems. Using antisense-based knockdown protocols and fusion proteins targeting both proteins, we have shown that MsContactin is selectively expressed by glial cells that ensheath the migratory neurons (expressing APPL), and that MsContactin-APPL interactions normally prevent inappropriate migration and outgrowth. These results provide new evidence that Contactins can function as authentic ligands for APP family proteins that regulate APP-dependent responses in the developing nervous system. They also support the model that misregulated Contactin-APP interactions might provoke aberrant activation of Go $\alpha$ and its effectors, thereby contributing to the neurodegenerative sequelae that typify AD.
\end{abstract}

Key words: Alzheimer's disease; embryo culture; G-protein; model system; neuronal guidance; neuronal-glial signaling

\section{Significance Statement}

Members of the amyloid precursor protein (APP) family participate in many aspects of neuronal development, but the ligands that normally activate APP signaling have remained controversial. This research provides new evidence that members of the Contactin family function as authentic ligands for APP and its orthologs, and that this evolutionarily conserved class of membrane-attached proteins regulates key aspects of APP-dependent migration and outgrowth in the embryonic nervous system. By defining the normal role of Contactin-APP signaling during development, these studies also provide the framework for investigating how the misregulation of Contactin-APP interactions might contribute to neuronal dysfunction in the context of both normal aging and neurodegenerative conditions, including Alzheimer's disease.

\section{Introduction}

A hallmark feature of Alzheimer's disease $(\mathrm{AD})$ is the accumulation of $\beta$-amyloid $(\mathrm{A} \beta)$ peptides that are cleaved from the amy-

Received March 5, 2016; revised June 22, 2016; accepted July 12, 2016.

Author contributions: J.M.R. and P.F.C. designed research; J.M.R. and T.L.S. performed research; J.M.R., T.L.S., and P.F.C. analyzed data; J.M.R. and P.F.C. wrote the paper.

This work was supported by National Institutes of Health Grants R01 AG025525 and R21 NS078363 to P.F.C., who also received support from an Oregon Health \& Science University Presidential Bridge Funding Award. J.M.R. received support from a grant from the Oregon Partners for Alzheimer's Research and from National Institute on Aging Training Grant \#AG023477. We thank Drs. Doris Kretzschmar and David Morton for critical input on the manuscript. We also thank Drs. Manzoor A. Bhat, Dr. Swati Banerjee, and Dr. Kalpana White for generously providing antibodies used in this work. We acknowledge Dr. Michael Kanost, Dr. Gary Blissard, and the Manduca sexta Genome Consortium for providing prepublication access to data from the Manduca genome project. We are grateful to Dr. Stefanie Kaech and Aurelie Snyder for their assistance with confocal microscopy and image analysis that was performed in the loid precursor protein (APP) and have neurotoxic effects in model systems, providing the basis for the "amyloid hypothesis" of $\mathrm{AD}$. In addition, growing evidence suggests that aberrant APPdependent signaling may also provoke neuronal dysfunction (Dawkins and Small, 2014; van der Kant and Goldstein, 2015). However, elucidating authentic roles for APP in the mammalian

Advanced Light Microscopy Core, Jungers Center at Oregon Health \& Science University, which is supported in part by National Institutes of Health Grant P30 NS061800.

The authors declare no competing financial interests.

Correspondence should be addressed to Dr. Philip F. Copenhaver, Cell, Developmental and Cancer Biology L-215, Oregon Health \& Science University, 3181 Southwest Sam Jackson Park Road; Portland, OR 97239. E-mail: copenhav@ohsu.edu.

DOI:10.1523/JNEUROSCI.0729-16.2016

Copyright $\odot 2016$ the authors $\quad 0270-6474 / 16 / 368757-19 \$ 15.00 / 0$ 
brain has been complicated by its overlapping expression with two related APP-like proteins (APLP1 and APLP2) that interact both in cis and trans (Heber et al., 2000; Herms et al., 2004; Soba et al., 2005), and by the discovery that different isoforms of APP are expressed by glial and endothelial cells as well as neurons (Forloni et al., 1992). In addition, the identities of authentic APP ligands are still controversial (Deyts et al., 2016).

As an alternative model for investigating neuronal-specific functions of APP family proteins, we have used the enteric nervous system (ENS) of the hawkmoth, Manduca sexta. During ENS development, $\sim 300$ enteric plexus neurons (EP cells) become distributed across the gut musculature via a stereotyped sequence of migration and outgrowth along eight preformed pathways (Copenhaver, 2007). Notably, the migratory EP cells robustly express APPL (APPLike, the sole insect ortholog of APP), whereby APPL colocalizes with the heterotrimeric G-protein Go $\alpha$ in their leading processes (Swanson et al., 2005; Ramaker et al., 2013). In previous work, we demonstrated that APPL and Go $\alpha$ directly interact both in vitro and in vivo, and we used embryo culture assays to show that APPL-Go $\alpha$ signaling prevents ectopic migration within the developing ENS (Ramaker et al., 2013). These studies support the model that APP family proteins function as unconventional Go $\alpha$-coupled receptors that regulate neuronal motility in a context-dependent manner (Okamoto et al., 1995; Brouillet et al., 1999). However, the ligands that normally activate APPL-Go $\alpha$ signaling responses remained undefined.

Although numerous proteins may bind APP (Ho and Südhof, 2004; Hoe et al., 2009; Lourenço et al., 2009; Rice et al., 2012), members of the Contactin family have been shown to interact with APP and its orthologs in both cultured neurons and the developing brain (Ma et al., 2008; Osterfield et al., 2008; Osterhout et al., 2015). Contactins are members of the Ig superfamily of cell adhesion molecules, typified by six Ig domains, four fibronectin type-III (FN-III) repeats, and a C-terminal glycosylphosphatidylinositol (GPI) lipid anchor (Shimoda and Watanabe, 2009). Mammals express six Contactins that have been ascribed a variety of roles, based in part on their developmental expression patterns (Hosoya et al., 1995; Yoshihara et al., 1995; Mohebiany et al., 2014). Different combinations of Contactins and APP family proteins have also been implicated in multiple aspects of neurogenesis and neuronal guidance (Ma et al., 2008; Osterfield et al., 2008; Mohebiany et al., 2014; Osterhout et al., 2015). However, because these proteins can interact promiscuously both in cis and trans, determining how a particular Contactin regulates APP-dependent responses has proven unexpectedly challenging. In contrast to mammalian systems, invertebrates express a single Contactin ortholog (Faivre-Sarrailh et al., 2004; Katidou et al., 2013; Ganot et al., 2015). Notably, Contactin expression in insects is confined to glial cells and epithelial cells (Faivre-Sarrailh et al., 2004; Banerjee et al., 2006), whereas APPL is expressed only by neurons (Luo et al., 1992; Swanson et al., 2005). We have now shown that Manduca Contactin (MsContactin) is selectively expressed by glial cells that ensheath the migratory EP cells (expressing APPL), and that both MsContactin and APPL are required to prevent ectopic migration and outgrowth. In addition, we have shown that soluble MsContactin fusion proteins bind APPL on the EP cells and inhibit their migration in an APPL-dependent and Go $\alpha$-dependent manner. These results provide new evidence that Contactins function as authentic ligands for APP family proteins in vivo, whereby Contactin-APP/L interactions regulate key aspects of neuronal guidance in the developing nervous system.

\section{Materials and Methods}

MsContactin and APPL fusion proteins. To generate MsContactin-Fc (MsCont-Fc) fusion constructs, we isolated a PCR fragment encoding the four FN-III-like domains of MsContactin from embryonic cDNA, using primers 5' -CTTCTCACACACAACTGCGGATTG-3' and 5' -ATTGTAAT GCGATAAGTGACC- $3^{\prime}$. This transcript was then subcloned into pcDNA3, in-frame with the signal sequence for MsContactin (at the $5^{\prime}$ end) and the sequence encoding human $\mathrm{Fc}$ (at the $3^{\prime}$ end). The resulting plasmid was transiently transfected into $293 \mathrm{~T}$ cells using Trans-IT LT1 Transfection Reagent (Mirus Bio LLC, catalog \#MIR 2300). Culture media from cells expressing secreted MsCont-Fc was collected after 1 week, purified with protein A Sepharose (GE Healthcare, \#17-0780-01), and subsequently dialyzed into defined saline ( $140 \mathrm{~mm} \mathrm{NaCl}, 5 \mathrm{~mm} \mathrm{KCl}, 28 \mathrm{~mm}$ glucose, $4 \mathrm{~mm}$ $\mathrm{CaCl}_{2}$, plus $5 \mathrm{~mm}$ HEPES, $\mathrm{pH}$ 7.4). To generate alkaline phosphatase (AP)tagged fusion constructs of Manduca APPL (sAPPL-AP), a PCR fragment that spanned the coding region containing the E1 and E2 domains (amino acids 1-508) of Manduca APPL was amplified from a pGEM-T construct encoding full-length APPL (Swanson et al., 2005), using primers 5' GCCGCAAACAT

GACGCGCGCCGTG-3' (which includes the signal sequence for APPL) and $5^{\prime}$-TCCATGCAATCCAAGGATGACATG-3'. This fragment was then subcloned into the pAPtag-2 expression vector (Genhunter, \#QV2), in-frame with the sequence encoding a C-terminal AP tag (encoding human placental AP). The resulting plasmid was transfected into $293 \mathrm{~T}$ cells, as described above. After $48 \mathrm{~h}$, media containing the secreted sAPPL-AP protein was harvested from the cultures, aliquoted, and frozen for subsequent use. Concentrations were monitored in SDS-PAGE gels by comparing serial dilutions of the sAPPL-AP medium with known concentrations of commercial AP (Genhunter, \#Q505).

Animals and immunohistochemistry. For immunofluorescence histochemistry, synchronous groups of embryos of either sex were collected from an in-house colony of $M$. sexta and staged according to published developmental markers (Copenhaver and Taghert, 1989b, 1990). When reared at $25^{\circ} \mathrm{C}$, embryogenesis is complete in $100 \mathrm{~h}$, whereby $1 \%$ of development is equivalent to $1 \mathrm{~h}$ postfertilization (hpf). Embryos were collected at stages spanning the periods of EP cell migration, axon outgrowth, and terminal differentiation (50-90 hpf); removed from their egg shells (chorions) and extraembryonic membranes in defined saline; and then dissected dorsally in Sylgard-coated chambers to expose the ENS, as previously described (Coate et al., 2007; Ramaker et al., 2013). The dissected embryos were then fixed with $4 \%$ paraformaldehyde (PFA) in PBS for $1 \mathrm{~h}$ at room temperature, then rinsed with PBS plus $0.1 \%$ Triton X-100 (PBST), unless otherwise noted. Embryos were incubated in blocking solution (PBST $+10 \%$ heat-inactivated normal horse serum and $0.01 \%$ sodium azide) for $1 \mathrm{~h}$ before application of the following primary antibodies: mouse anti-pan Manduca fasciclin II (Fas II: C3 monoclonal; which recognizes all Fas II isoforms; 1:20,000; Wright et al., 1999); guinea pig anti-Manduca Fas II (GPI-linked isoform; GPI-Fas II; 1:500-1:4000; Wright and Copenhaver, 2001); chicken anti-cAPPL (1: 2500; Swanson et al., 2005); rabbit anti-nAPPL (1:5000; \#21506; Ramaker et al., 2013); guinea pig anti-Drosophila REPO (Reversed polarity; 1:300; Banerjee et al., 2006); guinea pig anti-Drosophila Contactin (1:300 Faivre-Sarrailh et al., 2004), and rat anti-Drosophila ELAV (Embryonic lethal, abnormal vision; 1:500; Robinow and White, 1991). With the assistance of Yao-Hong Biotechnology, we also generated an affinity-purified polyclonal antibody against MsContactin (rabbit antiMsContactin), using a peptide epitope corresponding to amino acids 1156-1171 (ESERFLERTFRKAPQK; conjugated to KLH). This antibody was used at 1:200 for Western blots and 1:50 for immunohistochemistry. Its specificity was confirmed by labeling Western blots of MsCont-Fc fusion proteins (vs control fusion proteins), by preabsorption of the antibody against its peptide epitope (vs control peptides), and by knocking down MsContactin expression in GV1 cells (described below).

Primary antibodies were detected with secondary antibodies conjugated to Alexa Fluor-488, Alexa Fluor-555, or Alexa Fluor-647 (Invitrogen/Life Technologies) that were diluted 1:1000 in blocking solution, or with secondary antibodies conjugated to Dylight 549 (Jackson ImmunoResearch), diluted 1:800. Immunostained embryos were mounted in 
Elvanol (Banker and Goslin, 1998) and imaged with an Olympus FluoView 300 laser scanning confocal head, mounted on an Olympus BX51 microscope (located in the Live Cell Imaging Facility, Oregon Institute of Occupational Health Sciences, Oregon Health \& Science University). $Z$-stack projections of the confocal images were flattened in Fiji (Schindelin et al., 2012), using either maximum or average intensity projections. Images were adjusted for contrast and brightness and assembled into montages using Adobe Photoshop.

Immunoblotting and coimmunoprecipitation . To prepare Manduca lysates for immunoblotting assays, staged groups of embryos were removed from their eggshells and extraembryonic membranes and collected on dry ice. To prepare Drosophila lysates, the heads of adult wild-type flies were removed on dry ice and then stored at $-80^{\circ} \mathrm{C}$. Tissue samples were then solubilized in chilled NP-40 lysis buffer (1\% NP-40, $150 \mathrm{~mm} \mathrm{NaCl}, 50 \mathrm{~mm}$ Tris, $\mathrm{pH}$ 8, plus phosphatase and protease inhibitors) or Triton-X lysis buffer (1\% Triton X-100, $150 \mathrm{~mm} \mathrm{NaCl}, 50 \mathrm{~mm}$ Tris, $\mathrm{pH}$ 8), clarified by centrifugation $(10 \mathrm{~min}$ at $13,000 \mathrm{rpm})$, and used immediately or stored at $-20^{\circ} \mathrm{C}$ until use. Manduca GV1 cells were cultured for $48 \mathrm{~h}$ in 24 -well culture dishes in GV1 cell medium, consisting of $3.32 \mathrm{~g}$ of lactalbumin hydrolysate and 20 $\mathrm{ml}$ of $50 \times$ yeastolate per liter of Grace's insect medium (Thermo Fisher Scientific), plus $10 \%$ heat inactivated fetal bovine serum and $1 \%$ penicillinstreptomycin-neomycin, pH 6.5. Lysates of GV1 cells were prepared by adding NP-40 lysis buffer directly to the wells, after which the lysates were transferred to microfuge tubes, clarified by centrifugation, and used immediately or stored at $-20^{\circ} \mathrm{C}$ until use.

For coimmunoprecipitation experiments targeting MsContactin, Manduca embryos (65-70 hpf, 20 per condition) were isolated on dry ice, homogenized in NP40 lysis buffer or Triton-X lysis buffer, and the clarified supernatants were precleared with protein A/G beads (Santa Cruz Biotechnology, \#sc-2003). After a brief centrifugation to remove the beads ( $3000 \mathrm{rpm}$ for $15 \mathrm{~s}$ ), the supernatants were incubated with rabbit anti-MsContactin antibodies $(25 \mu \mathrm{g} / \mathrm{ml})$ for $3 \mathrm{~h}$ at room temperature or overnight at $4^{\circ} \mathrm{C}$; a similar concentration of purified IgG (Jackson Laboratories, \#1-000-003) was used as a negative control. For coimmunoprecipitation experiments targeting APPL, supernatants were incubated with chick anti-cAPPL antibodies $(0.05 \mu \mathrm{g} / \mathrm{ml})$; a similar concentration of purified IgY (Aves Labs, \#N-1010) was used as a negative control. Immune complexes were immunoprecipitated with PrecipHen beads (agarose-coupled goat anti-chicken; Aves Labs, \#P-1010). After antibody incubation, prewashed beads were applied to the supernatants for $1 \mathrm{~h}$, followed by brief centrifugation. The beads were then resuspended and boiled for $1 \mathrm{~min}$ in SDS sample buffer (1\% SDS, 10\% glycerol, $50 \mathrm{~mm}$ Tris, $\mathrm{pH}$ 6.7, 2.5\% $\beta$-mercaptoethanol) to elute bound proteins. Eluted proteins were then separated on either $10 \%$ or $4-12 \%$ BT-Criterion XT polyacrylamide gels (Bio-Rad), and the proteins transferred to PVDF or nitrocellulose membranes.

For immunoblotting (Western blotting), the following antibodies were diluted in TBST blocking buffer [Tris-buffered saline plus $0.1 \%$ polysorbate 20 (Tween) and 5\% Carnation dry milk], chick anti-cAPPL (1:2500; Swanson et al., 2005), rabbit anti-MsContactin (1:1000-1: 2000), guinea pig anti-Go $\alpha$ (1:100-1:250; Horgan et al., 1995), and mouse anti-pan Fas II (C3; 1:1000). After rinsing the blots in TBST, secondary antibodies coupled to horseradish peroxidase (HRP; Jackson ImmunoResearch; 1:10,000) were applied in TBST blocking buffer, and bound antibody complexes were detected using standard chemiluminescent protocols with either SuperSignal West Pico or West Femto substrates (Thermo Fisher Scientific).

Whole-mount in situ hybridization histochemistry. To generate antisense riboprobes for in situ hybridization histochemistry, doublestranded plasmid DNAs encoding Manduca GPI-Fas II and APPL were used as templates, as previously described (Wright et al., 1999; Swanson et al., 2005). In addition, the entire coding domain of MsContactin was subcloned into pGEM-T, using Gibson Assembly Cloning kits (New England Biolabs, \#ES510S). Plasmids were linearized and purified by gel extraction, and antisense probes were generated using T7 or SP6 RNA polymerase (New England Biolabs, \#M0207S and \#M02515), plus dithiothreitol, digoxigenin-11-UTP (DIG) labeling mix (Roche, \#11277073910), transcription buffer, and RNase inhibitors (Patel and Goodman, 1992; Wright et al., 1999). After precipitation (with $150 \mathrm{~mm}$
$\mathrm{LiCl}, 25 \mathrm{~mm} \mathrm{NaAc}, 100 \mu \mathrm{g} / \mathrm{ml}$ tRNA, and 75\% ETOH in double-distilled $\mathrm{H}_{2} \mathrm{O}$ ), the probes were resuspended in hybridization buffer ( $50 \%$ formamide, $5 \times$ SSC, $0.1 \%$ Tween, $50 \mu \mathrm{g} / \mathrm{ml}$ heparin, and $100 \mu \mathrm{g} / \mathrm{ml}$ tRNA in double-distilled $\mathrm{H}_{2} \mathrm{O}$ ) and stored at $-80^{\circ} \mathrm{C}$ until use. Embryos at stages between 55 and $75 \mathrm{hpf}$ were dissected to expose the ENS and fixed for $1 \mathrm{~h}$ in $4 \%$ PFA (electron microscopy grade; Electron Microscopy Sciences, $\# 15710$ ) plus $0.6 \%$ Triton X-100 in PBS, pH 8.0. After rinsing in PBS + $0.6 \%$ Triton $\mathrm{X}-100$, the preparations were incubated in hybridization buffer plus preboiled herring sperm solution $(200 \mu \mathrm{g} / \mathrm{ml})$ at $60^{\circ} \mathrm{C}$ for $1-2$ h. DIG-labeled antisense probes (diluted to a final concentration of 1:100 in hybridization buffer) were then added for overnight incubation at $60^{\circ} \mathrm{C}$. The preparations were subsequently rinsed extensively in hybridization buffer (first at $60^{\circ} \mathrm{C}$ and then room temperature), and then incubated overnight at $4^{\circ} \mathrm{C}$ in AP-conjugated sheep anti-DIG (Roche, \#11093274910; 1:2000) that had been preadsorbed against fixed skeletal muscle. Bound probes were detected by reacting the preparations with nitro blue tetrazolium plus 5-bromo-4-chloro-3-indolyl phosphate, diluted in AP developing buffer (Alkaline Phosphatase Conjugate Substrate Kit, Bio-Rad, \#1706432).

After processing, embryos were then mounted in SlowFade Gold Antifade Reagent (Life Technologies, \#S36936) and imaged using a Nikon Optiphot-2UD light microscope, equipped with Nomarski optics and a Nikon DXM1200F camera. Alternatively, for in situ hybridization histochemistry using fluorescent probes, preparations were incubated with antisense probes, then rinsed and incubated with HRP-conjugated Fab fragments of sheep anti-DIG (anti-DIG-POD; Roche, \#11207733910), diluted 1:300 in PBST. Preparations were reacted for 0.5-3 min with Cy3-conjugated tyramide signal amplification substrates (TSA plus Cy3 Kit NEL744001KT, PerkinElmer). Subsequently, the preparations were rinsed and immunohistochemically labeled with antibodies specific for glial or neuronal markers (as described above), then mounted in SlowFade Gold and imaged by confocal microscopy.

Embryo culture. Staged Manduca embryos (at $50 \mathrm{hpf}$ ) were removed from their eggshells and positioned dorsal-side up in Sylgard chambers containing warmed culture medium (defined saline plus $9.7 \%$ heatinactivated normal horse serum, $0.2 \%$ 20-hydroxyecdysone, $0.1 \%$ insulin, and $0.04 \%$ penicillin-streptomycin, $\mathrm{pH}$ 7.4; Ramaker et al., 2013). A small incision was then made in the dorsal epithelium to expose the developing ENS, and experimental reagents were applied directly to the premigratory EP cells until a full exchange of medium had been accomplished. The embryos were allowed to develop for an additional $12-48 \mathrm{~h}$ at $28^{\circ} \mathrm{C}$, then rinsed with normal culture medium and dissected along the midline to completely expose the ENS. The dissected preparations were fixed in 4\% PFA for $1 \mathrm{~h}$, rinsed in PBST, and immunostained with mouse anti-pan Fas II (C3; 1:20,000), which provides unambiguous labeling of the EP cells and their processes [expressing transmembrane Fas II (TM-Fas II)] , as well as the ensheathing glial cells (expressing GPI-Fas II; Wright et al., 1999; Ramaker et al., 2013). Anti-Fas II immunoreactivity was detected with biotinylated horse anti-mouse secondary antibodies (Vector Laboratories, BA-2000) diluted 1:200 in blocking solution, followed by an avidin-biotin reaction to amplify the signal (1:100; ABC kit, Vector Laboratories). The preparations were reacted with $1.4 \mathrm{~mm} \mathrm{3,3^{ \prime } -}$ diaminobenzidine in $0.001 \% \mathrm{H}_{2} \mathrm{O}_{2}$ and mounted in a glycerol-based medium on microscope slides. Conventional photomicrographic and camera lucida techniques were used to quantify the extent of neuronal migration and axon outgrowth along the midgut band pathways (Wright et al., 1999). Average values were calculated from replicate groups of embryos ( $N \geq 10$ per condition), and each experiment was repeated $\geq 3$ times. To measure ectopic growth by the EP cells, both the number of neurons and the cumulative distance of neurites that had traveled onto the interband muscles (between band pathways) were determined from camera lucida images, as previously described (Coate et al., 2008; Ramaker et al., 2013). The extent of ectopic outgrowth was normalized to the diameter of the midgut in each preparation to compensate for any distortions caused by our fixation and immunohistochemical staining methods (typically this distortion was $<10 \%$ of the average midgut diameters in each experiment). To ensure an unbiased analysis of the culture preparations, camera lucida images were generated and analyzed by two different investigators, both blinded to the treatment conditions. For 
analyses with $>2$ treatment groups, means were assessed using one-way ANOVA. Post hoc analysis used Student's two-tailed $t$ tests, applying Bonferroni's correction to obtain $p$ values adjusted for the number of pairwise comparisons.

Morpholino antisense oligonucleotides [morpholinos (MOs); Gene Tools] were designed against several regions of the mRNA sequences encoding MsContactin and APPL, respectively, and initially tested for their effectiveness and specificity in GV1 cells (at 1-50 $\mu \mathrm{M}$ ). After $48 \mathrm{~h}$ incubation with MOs targeting each gene, the cells were lysed in chilled NP-40 lysis buffer, and residual MsContactin and APPL levels were analyzed by Western blotting methods; the expression levels of several control proteins (including Fas II and actin) were used to monitor for off-target effects of the MOs. The most effective MsContactin-specific MO (GTTTAAGATGACAAACACCGGAGGT; targeting a sequence within the 5' UTR region upstream of the initiation codon) was subsequently used to inhibit MsContactin expression in cultured embryos (as described below). To inhibit APPL expression, we used an MO targeting a region in the Manduca Appl gene adjacent to the initiation codon (CCGcgttgcttcccaccagccc), which we previously showed was effective in inhibiting APPL expression in embryos (Ramaker et al., 2013).

To inhibit APPL or Contactin expression in cultured embryos, MOs were diluted to $100 \mu \mathrm{M}$ in culture medium. A small incision was made in the dorsal body wall of embryos placed in culture (at $53 \mathrm{hpf}$ ), and MOs were delivered into the EP cells with 0.6-1\% Endo-Porter (Gene Tools), as previously described (Coate et al., 2008). Based on our past studies, we estimate that this method results in a 10-fold dilution of the MOs, whereby the EP cells were exposed to a final concentration of $\sim 10 \mu \mathrm{M}$. Control embryos were treated with equivalent concentrations of standard control MOs plus Endo-Porter. For experiments combining MsCont-Fc stimulation with MO treatments, MsCont-Fc was added at a final concentration of $20 \mu \mathrm{g} / \mathrm{ml}$. To test the role of Go $\alpha$ in MsContactin-dependent responses, embryos were treated with MsCont-Fc plus pertussis toxin (PTX; intact molecule; Invitrogen) at a final concentration of $100 \mathrm{ng} / \mathrm{ml}$ in serum-free culture medium (Horgan et al., 1995).

For binding assays using sAPPL-AP fusion constructs, dissected embryos were fixed with 4\% PFA, rinsed with PBS $+0.5 \%$ acetylated BSA (Aurion BSA-c, Aurion) without Triton X-100, and then incubated for $90 \mathrm{~min}$ with $100 \mathrm{ng} / \mathrm{ml}$ sAPPL-AP (Flanagan et al., 2000). Purified AP (Genhunter, \#Q302) and vehicle control medium served as negative controls. For binding assays using MsCont-Fc fusion constructs, dissected embryos were fixed with $4 \%$ PFA, permeabilized briefly with PBS plus $0.1 \%$ Triton $\mathrm{X}-100$, and then incubated for $2 \mathrm{~h}$ with $400 \mu \mathrm{g} / \mathrm{ml}$ MsCont-Fc in defined saline. Matched sets of preparations were treated (1) with medium alone, (2) with ChromPur human IgG Fc fragments (Jackson ImmunoResearch, \#009-000-008); or (3) with a variety of control Fc fusion proteins, including MsEph-Fc and MsEphrin-Fc (Coate et al., 2008). The embryos were subsequently postfixed with PFA for 30-60 min. Preparations treated with AP fusion proteins were incubated with mouse anti-human placental AP (1:200; Thermo Fisher Scientific, \#MA1-19354), which was detected with Alexa 488-conjugated antimouse secondary antibodies. Preparations treated with Fc fusion proteins were incubated with 549-conjugated goat anti-human IgG Fc antibodies (Abcam, \#ab98563) or with HRP-conjugated anti-Fc antibodies (1:1000; Jackson ImmunoResearch), followed by a reaction with tyramide signal amplification substrates for 2 min (Coate et al., 2007). The preparations were subsequently counterstained with antibodies specific for neuronal and glial markers (as described above) and imaged by confocal microscopy, using identical laser-intensity settings within the linear range of each channel for all preparations in an experiment. To quantify the relative levels of MsCont-Fc signals in MO-treated preparations, three separate images were obtained per preparation, each consisting of three optical sections spanning $0.6 \mu \mathrm{m}$ total tissue thickness. Maximum intensity projections were generated using Fiji software and uniformly adjusted for brightness and contrast by an investigator blinded to the treatment conditions. Regions of interest (ROIs) in each preparation were manually selected that encompassed single EP cells (on the mid-dorsal muscle bands) or identical areas on the adjacent interband muscles. Total signal intensities within the ROIs were calculated sepa- rately for each fluorescent channel, and background levels (determined from the control ROIs) were subtracted from the ROI values encompassing the EP cells. After unblinding the treatment conditions, average values for the relative levels of MsCont-Fc binding activity were determined for each condition, and statistical differences between groups calculated using Student's $t$ tests.

\section{Results}

The Manduca ENS as a model system for investigating neuronal and glial migration

The differentiation of the Manduca ENS involves a precisely choreographed sequence of neuronal and glial migration (Fig. 1A), regulated by attractive and repulsive guidance cues encountered by the motile cells during different phases of their differentiation (Copenhaver and Taghert, 1989b; Copenhaver, 1993; Wright et al., 1999; Coate et al., 2008). Between 30 and $40 \mathrm{hpf}$, a packet of $\sim 300$ neurons (EP cells) delaminates from a neurogenic placode in the dorsal foregut, coincident with their terminal mitoses (Copenhaver and Taghert, 1990). Over the next $15 \mathrm{~h}$ (from 40 to $55 \mathrm{hpf}$ ), this packet of neurons spreads bilaterally around the foregut (Fig. $1 A_{1}$, magenta cells), gradually aligning with eight preformed muscle bands (b) on the midgut surface. Then between 55 and $65 \mathrm{hpf}$, small groups of EP cells rapidly migrate in a chain-like Manner along each of the midgut muscle bands, while a few neurons migrate radially onto the foregut musculature (Fig. $\left.1 A_{2}\right)$. Throughout the migratory period, the EP cells extend and retract numerous filopodia onto the adjacent gut musculature, but they remain closely associated with their band pathways while generally avoiding the interband regions (ib). Concurrently, a population of proliferating glial cells (green cells) spreads from the foregut onto the pathways established by the neurons. Between 65 and $70 \mathrm{hpf}$, the EP cells transition from active locomotion to a prolonged phase of outgrowth (Fig. $1 A_{3}$ ), during which they extend fasciculated bundles of axons posteriorly along the length of the midgut. In some preparations, a small number of neurons (typically 1-3) remain within the nerve arches between adjacent bands on the foregut (open arrowheads) and occasionally extend processes directly onto the midgut. Only subsequently do the neurons extend terminal branches laterally off the bands (from 75 to $100 \mathrm{hpf}$; Fig. $1 A_{4}$ ), providing a diffuse innervation of the midgut musculature. The glial cells also continue to elaborate processes around the dispersed groups of EP cells, ultimately ensheathing the neuronal somata (Copenhaver, 1993).

In previous studies, we showed that APPL expression is initially upregulated in EP cells as they spread around the foregut, and it remains elevated throughout their subsequent phases of migration and axon elongation (Swanson et al., 2005; Ramaker et al., 2013). We also showed that full-length APPL traffics into the leading processes and growth cones of the motile EP cells, where it functions as a neuronal guidance receptor that helps restrict inappropriate outgrowth onto the interband regions of the midgut (Ramaker et al., 2013). Figure $1 B_{1}$ shows the developing ENS of an embryo at $65 \mathrm{hpf}$ (during the transition from migration to axon outgrowth), immunostained with antibodies targeting APPL (magenta) and GPI-Fas II (green). As previously reported, insect APPL is expressed exclusively by neurons (Luo et al., 1990; Swanson et al., 2005), while GPI-Fas II is expressed exclusively by the ensheathing glial cells at this stage (Wright and Copenhaver, 2000), providing specific markers for the different cellular components of the ENS.

\section{Identification of MsContactin as a candidate ligand for APPL}

To identify membrane-associated proteins that interact with APPL, we created a fusion construct containing the secreted ect- 


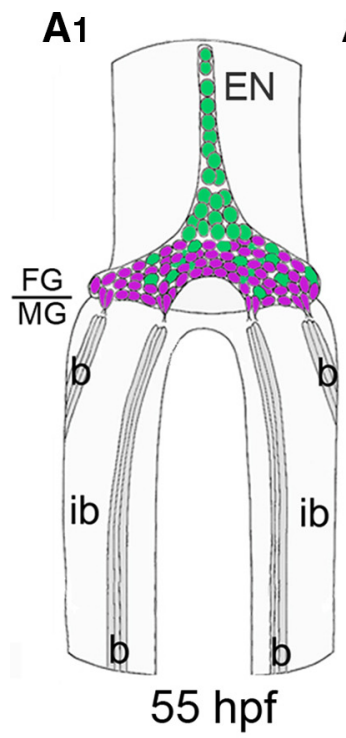

A2

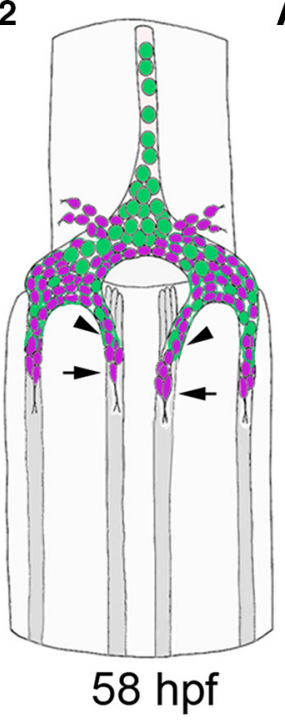

A3

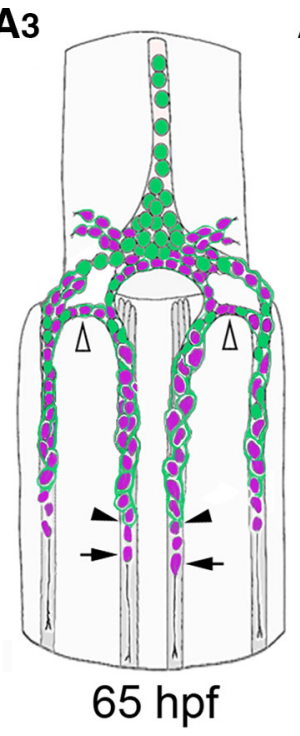

A4

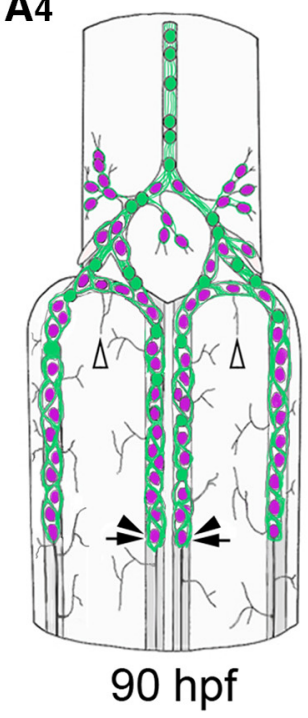

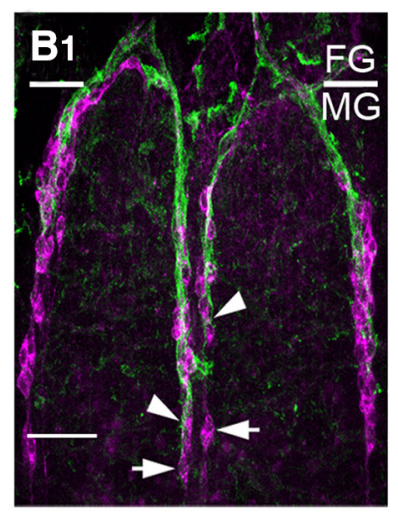
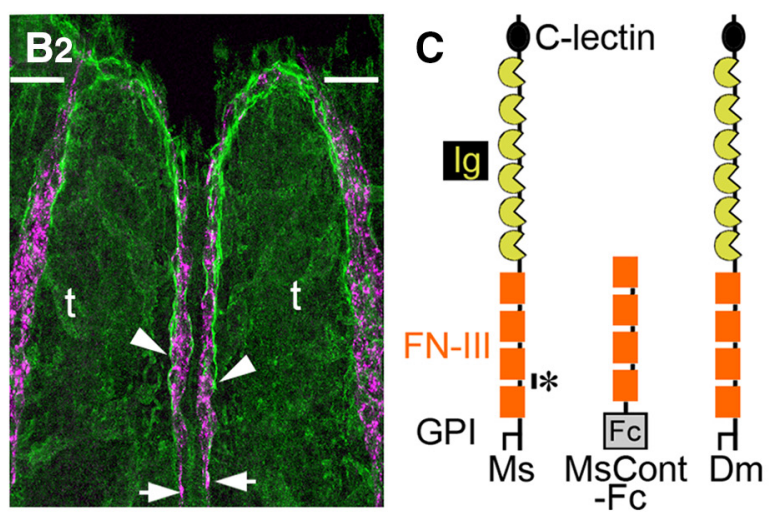

है

D

FN1

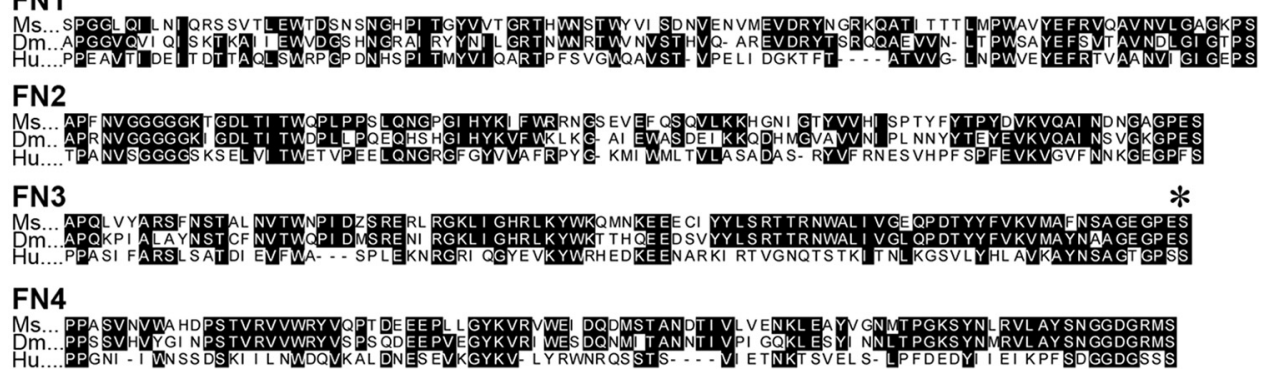

Figure 1. Identification of MSContactin as a candidate ligand for APPL in the developing ENS. A, Schematic representation of neuronal and glial cell migration in the embryonic ENS of Manduca. Panels show dorsal views of the embryonic gut at progressive stages of development; at $25^{\circ} \mathrm{C}$, embryogenesis is completed in $100 \mathrm{hpf} . A 1$, By $55 \mathrm{hpf}$, the postmitotic EP cells (magenta) have emerged from a neurogenic placode and spread bilaterally as a packet to encircle the foregut, adjacent to the foregut-midgut boundary (FG/MG). EN, Esophageal nerve of the foregut. Groups of EP cells preferentially align their leading processes with eight longitudinal muscle bands (b) that have coalesced on the midgut, while avoiding the adjacent interband regions (ib). Only the four dorsal bands of the midgut are shown. Concurrently, a population of glial precursors (green) begins to spread among the EP cells on the foregut. A2, By 58 hpf, subsets of EP cells have begun to migrate in a chain-like manner along each of the muscle bands, while proliferating glial cells spread along the pathways established by the neurons. A small number of EP cells also migrate along radial muscle fibers on the midgut. $A 3$, By $65 \mathrm{hpf}$, the EP cells have completed migration and have transitioned to a prolonged period of axon outgrowth, while the glial cells continue to elaborate processes that surround the neuronal cell bodies. $A 4$, By $90 \mathrm{hpf}$, the EP cells have extended terminal branches laterally to innervate the interband musculature. The glial cells fully ensheath the neuronal cell bodies but not their posterior axons or their synaptic terminals on the interband musculature. Black arrows in A2-A4 indicate the leading migratory neurons on the mid-dorsal pathways; black arrowheads indicate the leading glial processes ensheathing the neuronal somata. White arrowheads indicate EP cells in the arch nerves of the enteric plexus that occasionally extend processes into the interband region. B1, Whole-mount Manduca embryo (at 65 hpf) immunostained with anti-APPL (magenta) and anti-GPI-Fas II (green). Anti-APPL specifically labels the migratory EP cells (arrows), while anti-GPI-Fas II labels glial processes (arrowheads) that have begun to ensheath the neurons. B2, Matched embryo labeled with anti-APPL (magenta) and anti-dContactin (green). Anti-dContactin labels the glial processes (similar to anti-GPI-Fas II) but also produces elevated levels of background staining on adjacent tissues, including the tracheolar cells (t) that invest the midgut at this stage. C, Schematic representation of Contactin family members, indicating their evolutionarily conserved pattern of six lg domains, four FN-III domains, and GPI attachment sites. Ms, M. sexta; Dm, Drosophila melanogaster; $\mathrm{Hu}$, human. Manduca and Drosophila Contactins also contain an N-terminal C-type lectin domain of unknown function. MsCont-Fc, A soluble fusion protein consisting of the four FN-III domains of MsContactin plus a C-terminal human Femotif. D, Sequence alignment of the four FN-III domains in MsContactin (Ms), dContactin (Dm), and human Contactin-3 (Hu). Black boxes indicate identical amino acid residues. Asterisks in $($ and $\boldsymbol{D}$ indicate the position of the peptide epitope used to generate anti-MsContactin antibodies (also conserved in dContactin). Scale bar, $40 \mu \mathrm{m}$. 

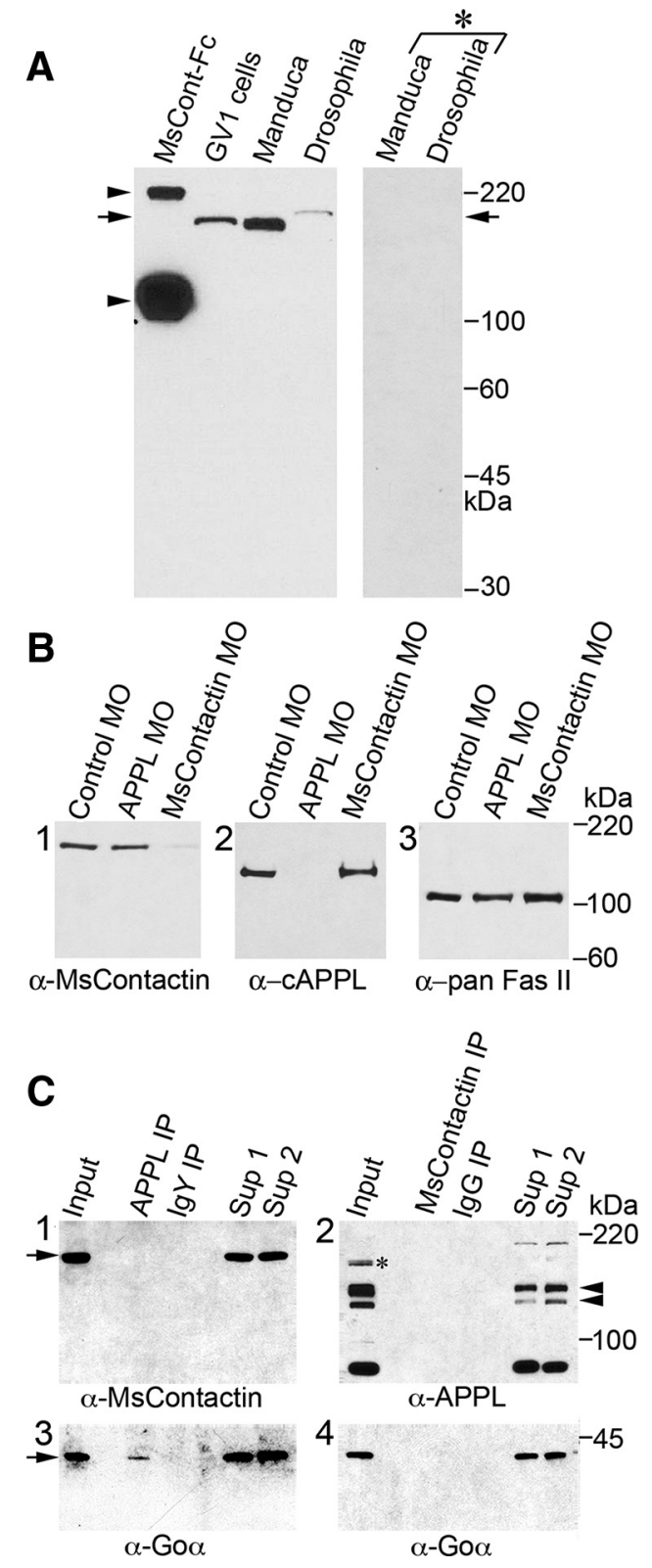

Figure 2. anti-MsContactin antibodies recognize a single Contactin ortholog in Manduca and Drosophila. A, Western blot probed with affinity-purified anti-MsContactin. Lane 1, MsCont-Fc fusion proteins are detected both as monomers (110 kDa) and dimers (220 kDa). Lanes 2 and 3, Endogenously expressed MsContactin is detected at $\sim 175 \mathrm{kDa}$ in Manduca GV1 cells (lane 2) and Manduca embryos (lane 3). The size of this protein is consistent with extensive post-translational modification of the core protein (predicted size, $142 \mathrm{kDa}$ ), as reported for $\mathrm{dContactin}$. Lane 4, dContactin is detected at $\sim 180 \mathrm{kDa}$ from head lysates, consistent with published studies (Faivre-Sarrailh et al., 2004). Lanes 5 and 6, Western blot labeled with antiMsContactin antibodies that were preadsorbed against their peptide epitope $\left({ }^{*}\right)$ does not label any proteins in lysates of Manduca embryos (lane 5) or Drosophila heads (lane 6), loaded at the same concentrations as in lanes 3 and 4 . $\boldsymbol{B}$, Replicate cultures of Manduca GV1 cells treated with different MOs as indicated, and then lysed and immunoblotted with anti-MsContactin (B1), anti-APPL (B2), or anti-pan Fas II (B3). B1, MsContactin was detected at $\sim 175$ kDa in GV1 cells treated with control MOs and APPL-specific MOs, but was substantially reduced in cells treated with MsContactin-specific M0s. B2, APPL was detected at $\sim 135 \mathrm{kDa}$ in cells treated with control MOs and MsContactin MOs, but not in cells treated with APPL MOS. B3, Similar levels of Fas Il were detected at $\sim 100 \mathrm{kDa}$ in cells treated with control MOs, APPL MOs, or MsContactin MOs. The anti-pan Fas II antibody used in this assay recognizes both transmembrane and GPIlinked isoforms (not distinguishable in this immunoblot). C1, Embryonic lysates were immunoprecipitated with anti-APPL or control lgY and labeled with anti-MsContactin. Lane 1, "Input" shows endogenous MsContactin at $\sim 175 \mathrm{kDa}$. Lanes 2 and 3, Proteins immunoprecipitated with anti-APPL or control $\lg Y$ did not include detectable MsContactin. Lanes 4 and 5, odomain of Manduca APPL, fused to an AP tag (sAPPL-AP). We then used this construct to screen a plasmid expression library in COS7 cells (prepared from embryonic Manduca cDNA), following the "panning" protocols of Flanagan and colleagues (Flanagan and Cheng, 2000; Osterfield et al., 2008). One of our strongest positive clones encoded M. sexta Contactin (MsContactin). As noted above, several Contactin family members have been shown to interact with APP family proteins in vertebrate systems (Ma et al., 2008; Osterfield et al., 2008; Osterhout et al., 2015), suggesting that MsContactin might serve a similar function in the developing ENS. Accordingly, we obtained a full-length cDNA clone encoding MsContactin (1311 aa) by RT-PCR (GenBank accession \#KU840799) and confirmed the sequence by comparison with the Manduca genome (https://i5k. nal.usda.gov/Manduca_sexta). As illustrated in Figure $1 C$, the predicted structure of MsContactin contains six Ig domains, four FN-III repeats, and a GPI attachment site at its $\mathrm{C}$ terminus, similar to other Contactin family members (Shimoda and Watanabe, 2009; Zuko et al., 2011). MsContactin also contains a C-type lectin domain at its $\mathrm{N}$ terminus that was originally identified in Drosophila Contactin (dContactin); the function of this domain is unknown (Faivre-Sarrailh et al., 2004). The primary amino acid sequence for MsContactin is $58 \%$ identical to dContactin and $\sim 31 \%$ identical to mouse and human Contactin-3 and Contactin-4 (the closest mammalian orthologs). Sequence similarities were considerably stronger within the four FN-III domains (Fig. 1D), including the conserved motifs flanking each FN-III domain.

As an initial means of exploring Contactin expression in the developing ENS, we coimmunostained Manduca embryos with antiAPPL to label the EP cells (Fig. $1 B_{2}$, magenta) and an antiserum against dContactin (generously provided by Dr. Manzoor Bhat and colleagues, University of Texas Health Center, San Antonio, Texas). Unexpectedly, we found that anti-dContactin (Fig. $1 B_{2}$, green) produced a pattern of immunoreactivity that closely matched the expression of GPI-Fas II (Fig. $1 B_{1}$ ), labeling the glial processes surrounding the EP cells but not the neurons themselves. However, because both the anti-dContactin and anti-GPI-Fas II antibodies were produced in the same host species, we generated a new affinitypurified antibody against a conserved region shared by insect Contactins, spanning the third and fourth FN-III domains in MsContactin (amino acids 1156-1171; Fig. 1C,D, asterisks). In Western blots of lysates prepared from Manduca GV1 cells and embryos (collected at $65 \mathrm{hpf}$ ), anti-MsContactin labeled a single band at $\sim 175 \mathrm{kDa}$ (Fig. 2A, arrow), compared with the predicted size of the

$\leftarrow$

MsContactin was still detectable in supernatants after immunoprecipitation with anti-APPL or control IgY. C2, Western blot of Manduca embryonic lysates that were immunoprecipitated with either anti-MsContactin or control lgG and labeled with anti-APPL. Lane 1, "Input" shows mature (fully glycosylated) APPL at $135 \mathrm{kDa}$ (upper arrowhead) and an immature full-length form at $110 \mathrm{kDa}$ (as previously described; Swanson et al., 2005). Asterisk indicates a larger band detectable in midembryonic stages; a smaller band at $80 \mathrm{kDa}$ is nonspecific to anti-APPL. Lanes 2 and 3, Proteins immunoprecipitated with anti-MsContactin or control lgG did not include detectable APPL. Lanes 4 and 5, Both mature and immature forms of APPL were readily detectable in supernatants after immunoprecipitation with anti-MsContactin or control lgG. C3, Lower portion of immunoblot shown in C1, labeled with anti-Go $\alpha$. Lane 1, "Input" shows endogenous $\mathrm{G}_{0} \alpha$ at $\sim 41 \mathrm{kDa}$. Lanes 2 and 3, Go $\alpha$ coimmunoprecipitated with APPL but not control IgY, as previously demonstrated (Ramaker et al., 2013). Lanes 4 and 5, Go $\alpha$ was still abundant in supernatants after immunoprecipitation with anti-APPL or control IgY. C4, Lower portion of immunoblot shown in $\mathbf{2}$, labeled with anti-Go $\alpha$. Lane 1, "Input" shows endogenous Go $\alpha$ at $\sim 41 \mathrm{kDa}$. Lanes 2 and 3, Go $\alpha$ was not coimmunoprecipitated by anti-MsContactin or control lgG. Lanes 4 and 5, Go $\alpha$ was abundant in supernatants after immunoprecipitation with anti-MsContactin or control lgG. 

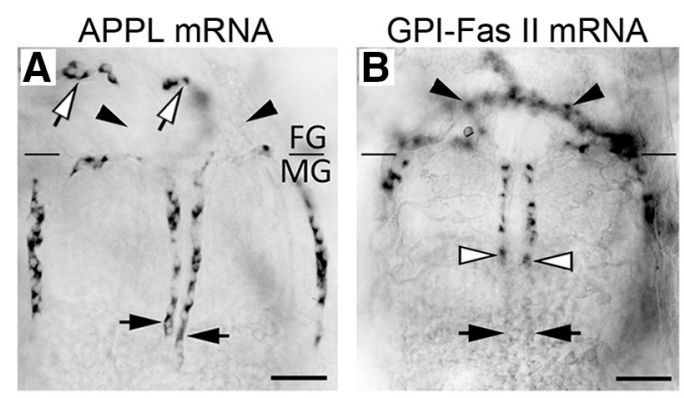

$\alpha-C A P P L$

Contactin mRNA Contactin mRNA glial markers
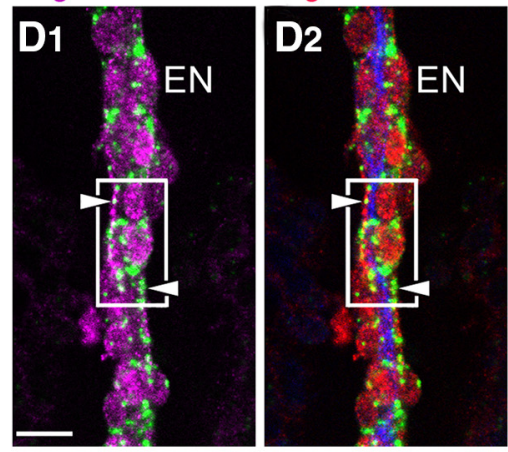

$\alpha-E L A V$

APPL MRNA glial markers

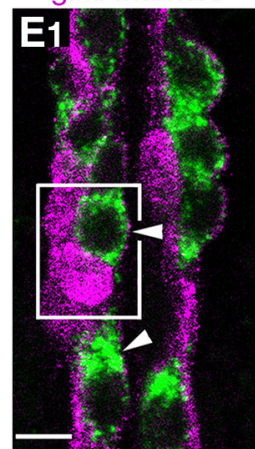

glial markers
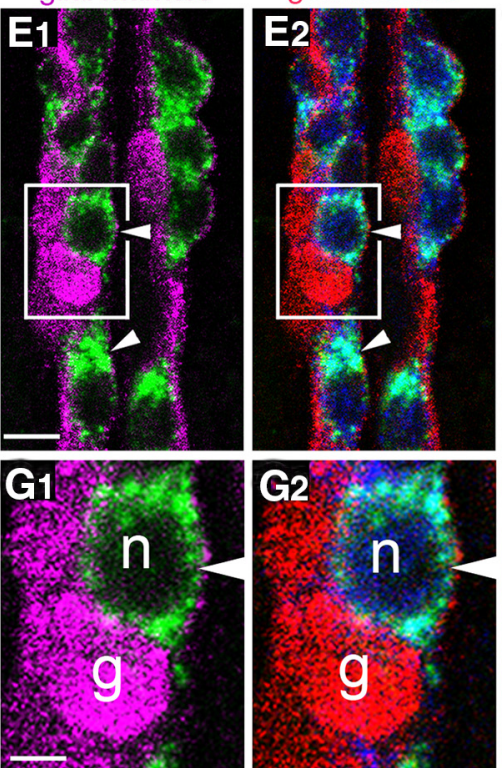

MsContactin mRNA

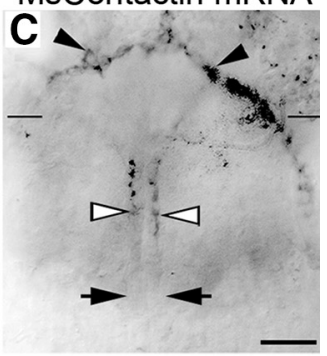

$\alpha-\mathrm{CAPPL}$
Contactin mRNA glial markers

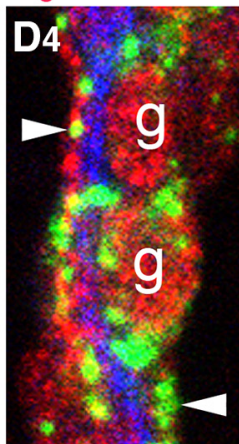

$\alpha$-ELAV

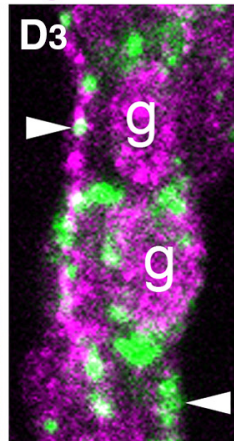

Contactin mRNA glial markers

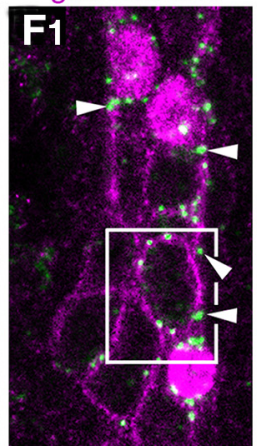

glial markers
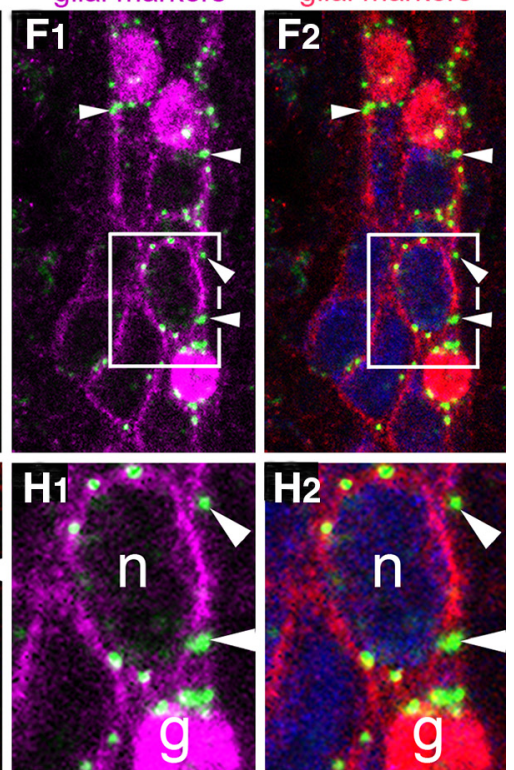

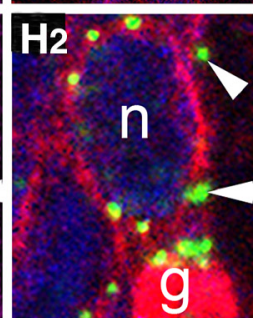

Figure 3. Cell type-specific expression of mRNA encoding APPL and MsContactin in the developing ENS. $A-C$, The developing ENS of filleted embryos (65 hpf) labeled with digoxigenin-labeled riboprobes specific for different genes involved in EP cell migration. $A$, mRNA encoding APPL is exclusively expressed by the EP cells, including subsets of neurons that migrated along radial muscles on the foregut (white arrows) and onto the muscle band pathways on the midgut (black arrows). Black arrowheads indicate branches of the enteric plexus on the foregut that contain unlabeled glial cells but are devoid of EP cells at this stage. $\boldsymbol{B}$, mRNA encoding GPI-Fas II is exclusively expressed by the enteric glial cells, including glial subsets that ensheath the enteric plexu nerves on the foregut (black arrowheads) and other glial populations have spread along the EP cell pathways on the midgut (white arrowheads). The glial cells slightly trail the leading migratory neurons (black arrows; compare with $\boldsymbol{A}$ ). $\boldsymbol{C}$, mRNA encoding MsContactin is expressed in the same pattern as GPI-Fas II by the enteric glial cells ensheathing the foregut nerves (black arrowheads) and spreading along the midgut band pathways (white arrowheads). Black arrows indicate the leading EP cells that do no express MsContactin mRNA. FG/MG, Foregut-midgut boundary. D, Esophageal nerve (EN) of the foregut labeled by fluorescent in situ hybridization with riboprobes specific for MsContactin $\mathrm{mRNA}$, followed by immunohistochemical staining with a combination of glial markers (anti-REPO plus anti-GPI-Fas II) and anti-CAPPL as a neuronal-specific marker. The esophageal nerve contains ascending axons from some EP cells and descending axons from neurons in more anterior enteric ganglia on the foregut but no neuronal somata. $\boldsymbol{D}_{1}$, Lower-magnification image of the esophageal nerve labeled with MsContactin-specific riboprobes (green) core protein of $\sim 142 \mathrm{kDa}$. Likewise, antiMsContactin labeled a single band at $\sim 180$ $\mathrm{kDa}$ in Drosophila lysates, compared with the predicted core protein for dContactin of $155 \mathrm{kDa}$. As previously reported (FaivreSarrailh et al., 2004), the larger apparent size of endogenously expressed dContactin results from extensive $N$-glycosylation at residues conserved in MsContactin. Similar results were obtained using anti-dContactin, although this antibody also labeled several additional nonspecific bands in Manduca lysates (J. M. Ramaker, T. L. Swanson, P. F. Copenhaver, unpublished observations).

To demonstrate the specificity of our anti-MsContactin antibody, we also generated an $\mathrm{Fc}$-coupled fusion protein containing the four FN-III domains of MsContactin (MsCont-Fc; Fig. 1C). As shown in Figure 2A (lane 1), anti-MsContactin detected both the monomeric $(110 \mathrm{kDa})$ and dimeric $(\sim 220 \mathrm{kDa})$ forms of this fusion protein (arrowheads), but did not label control Fc proteins (data not shown). In contrast, preadsorbing our anti-MsContactin antibody against its peptide epitope eliminated its ability to label proteins in Western blots of

and glial markers (magenta). $\boldsymbol{D}_{2}$, The same preparation counterstained with anti-cAPPL to label the fasciculated axons (blue). $\boldsymbol{D}_{3}, \boldsymbol{D}_{4}$, Higher-magnification image of the boxed regions in $\boldsymbol{D}_{\mathbf{1}}$ and $\boldsymbol{D}_{\mathbf{2}}$. Arrowheads indicate punctate in situ hybridization signal within glial processes surrounding the fasciculated axons. g, Glial cell body. $\boldsymbol{E}_{1}, \boldsymbol{E}_{2}$, EP cells and surrounding glial cells on the mid-dorsal bands of an embryo at 65 hpf, labeled by fluorescent in situ hybridization with riboprobes specific for APPL mRNA (green), followed by immunohistochemical staining with neuronal and glial markers (65 hpf). $\boldsymbol{E}_{1}$, APPL mRNA (green) is localized to migrating neurons ( $n$; arrowheads) but not the interspersed glial cells (magenta), which were immunostained with a combination of anti-REPO and anti-GPI-Fas II antibodies (labeling glial nuclei and processes, respectively). $\boldsymbol{E}_{2}$, The same preparation counterstained with the neuronal marker anti-ELAV (blue), which labels the EP cells (expressing APPL mRNA; green) but not the glial cells (shown in red). $\boldsymbol{F}_{1}, \boldsymbol{F}_{2}$, EP cells and surrounding glial cells labeled with riboprobes specific for MsContactin mRNA, followed by immunohistochemical staining with the same neuronal and glial markers shown in $E$. $F_{1}$, MsContactin mRNA (green) is localized to the cytoplasmic processes of glial cells (arrowheads) that also coimmunostained with anti-REPO and anti-GPI-Fas II (magenta). $\boldsymbol{F}_{2}$, The same preparation counterstained with anti-ELAV indicates that MsContactin mRNA is detectable in the glial cells (shown in red) but not the neurons (blue). $G_{1}, G_{2}$, Higher-magnification view of the boxed regions in $\boldsymbol{E}_{1}$ and $\boldsymbol{E}_{2}$. EP neurons (n) express APPL-specific mRNA (green) and ELAV (blue); glial cells (g) express REPO and antiGPI-Fas II (magenta/red). $\boldsymbol{H}_{\boldsymbol{1}}, \boldsymbol{H}_{2}$, Higher-magnification view of boxed region on $\boldsymbol{F}_{1}$ and $\boldsymbol{F}_{2}$. Glial cells $(\mathrm{g})$ express MsContactin-specific mRNA (green), plus REPO and anti-GPIFas II (magenta/red). EP neurons (n) express ELAV (blue). $\boldsymbol{D}-\boldsymbol{H}$, One optical section. Scale bars: $\boldsymbol{A}-\boldsymbol{C}, 40 \mu \mathrm{m} ; \boldsymbol{D}_{1}, \boldsymbol{D}_{2}, \boldsymbol{E}, \boldsymbol{F}$, $20 \mu \mathrm{m} ; \boldsymbol{D}_{\mathbf{3}}, \mathbf{D}_{4}, \mathbf{G}, \boldsymbol{H}, 5 \mu \mathrm{m}$. 
Manduca and Drosophila lysates (Fig. 2A, asterisk). Last, knocking down MsContactin mRNA expression in GV1 cells with MOs almost completely eliminated labeling of the $175 \mathrm{kDa}$ band by antiMsContactin (Fig. 2 $B_{1}$, lane 3), whereas control MOs and MOs targeting APPL mRNA had no consistent effect on MsContactin levels (Fig. $2 B_{1}$, lanes 1,2 ). These results indicate that our antiMsContactin antibody specifically labels MsContactin but not other proteins expressed by developing embryos.

\section{Cell type-specific expression of APPL and MsContactin in the developing ENS}

Given previous evidence that mammalian Contactins can interact with APP family proteins both in cis (as candidate coreceptors) and trans (as potential ligand-receptor partners), we investigated which cell types express MsContactin and APPL in more detail. Using identically staged sets of embryos (at $65 \mathrm{hpf}$ ), we initially performed whole-mount in situ hybridization histochemistry with DIG-labeled antisense riboprobes targeting APPL, MsContactin, and GPI-Fas II mRNA. As previously described (Swanson et al., 2005), riboprobes specific for APPL mRNA labeled the migratory EP cells that had dispersed along the midgut muscle bands (Fig. $3 A$, black arrows) and along radial muscles on the foregut (white arrows), but not the trailing glial populations occupying the branching nerves of the enteric plexus on the foregut (black arrowheads). In contrast, riboprobes specific for GPI-Fas II mRNA (Wright and Copenhaver, 2000) produced a complementary pattern of staining, labeling the glial cells within the enteric plexus nerves (Fig. 3B, black arrowheads) and along the pathways pioneered by the EP cells on the midgut (Fig. 3B, white arrowheads). Notably, riboprobes specific for MsContactin mRNA (Fig. 3C) produced a pattern of staining that closely matched the distribution of GPI-Fas II mRNA, labeling glial populations within the foregut plexus nerves (black arrowheads) and associated with the midgut pathways (white arrowheads), but not the leading EP cells (black arrows).

To demonstrate that MsContactin is specifically expressed by the enteric glial cells but not the EP cells, we subsequently used fluorescence in situ hybridization histochemistry to label embryos with riboprobes targeting mRNAs encoding either MsContactin or APPL, and then counterstained the preparations with antibodies against our neuronal and glial markers. Initially, we focused on the esophageal nerve of the foregut (EN; Fig. 1A), which contains fasciculated axons from some EP cells and neurons in more anterior ganglia enwrapped by glial cells, but no neuronal cell bodies (Copenhaver and Taghert, 1989a, 1991). As shown in Figure 3D, riboprobes specific for MsContactin mRNA strongly labeled the ensheathing glial cells (magenta/red), which were double-immunostained with anti-REPO (to label glial nuclei) and anti-GPI-Fas II (to label glial processes), but not the axons themselves (immunostained with anti-APPL; blue). The punctate nature of the in situ hybridization signal was due in part to the tyramide-based amplification method used to label these preparations, but it might also reflect local concentrations of MsContactin mRNA in the glial processes (white arrowheads), similar to the well documented transport of RNA granules in mammalian glia (Smith, 2004; Carson et al., 2008; Quraishe et al., 2016). As expected, we detected no APPL mRNA within the esophageal nerve (data not shown).

Using these methods to label the developing enteric plexus, we found that riboprobes specific for APPL mRNA strongly labeled the EP cells on the midgut (Fig. $3 E, G$, green), which were counterstained with ELAV (Fig. $3 E_{2}, G_{2}$, blue), but not the adjacent glial cells (magenta/red). By comparison, MsContactin mRNA was restricted to the ensheathing glial cells (Fig. $3 F, H$, green), including punctate labeling within glial processes surrounding the neurons (arrowheads). These results indicate that MsContactin is only expressed by glial cells within the developing ENS, and confirm that APPL is a neuronal-specific protein (as previously reported; Luo et al., 1990; Swanson et al., 2005).

As a complementary strategy, we also triple-immunostained the developing ENS with antibodies against APPL (to label the EP cells), GPI-Fas II (to label the enteric glial cells), and our new antibody against MsContactin (Fig. 4). At lower magnification, we could readily detect MsContactin within glial processes that extended around the neuronal somata expressing APPL (Fig. $4 A, B$, arrowheads). At higher magnification, anti-APPL clearly labeled the EP cells and their processes (Fig. $4 C_{1}, D_{1}$ ), whereas anti-GPI-Fas II (Fig. $4 C_{2}, D_{2}$ ) and anti-MsContactin (Fig. $4 C_{3}, D_{3}$ ) both labeled the surrounding glial processes. In the course of these studies, we also noted that the distribution of MsContactin on the glial membranes was more restricted than GPI-Fas II, whereby MsContactin immunoreactivity was concentrated within glial processes at the margins of the ensheathed columns of neurons (Fig. $4 C_{4}, D_{4}$, arrowheads). Although this pattern might be caused by partial masking of MsContactin at points of cell-cell contact, it could also result from the selective localization of MsContactin within specific subdomains of the glial processes. These results are also consistent with the model that neuronal APPL interacts only transiently with glial MsContactin, resulting in a repulsive response by the migratory EP cells (as described below).

Because APP and Contactin family members are often coexpressed by the same cell types in mammalian systems, they can be readily coimmunoprecipitated from mouse brain lysates (Ma et al., 2008; Osterfield et al., 2008; Shimoda et al., 2012; Osterhout et al., 2015). In contrast, we found that antibodies against APPL did not coimmunoprecipitate MsContactin from Manduca embryonic lysates (Fig. $2 C_{1}$, arrow), nor did anti-MsContactin coimmunoprecipitate APPL (Fig. $2 C_{2}$, arrowheads), complementing our evidence that the two proteins are expressed by different cell types (Figs. 3,4 ). In contrast, anti-APPL reliably coimmunoprecipitated Go $\alpha$ (Fig. 2C $_{3}$, whereas anti-MsContactin did not (Fig. $2 C_{4}$ ), supporting our earlier work that APPL and Go $\alpha$ directly interact in developing neurons (Ramaker et al., 2013).

\section{Glial expression of MsContactin is developmentally regulated, coincident with EP cell migration}

In previous studies, we showed that APPL expression in the EP cells is dramatically upregulated during their migration and during axon outgrowth onto the midgut bands (55-65 hpf), but it is eventually downregulated as the neurons extend terminal branches onto the interband musculature (85-100 hpf; Swanson et al., 2005; Ramaker et al., 2013). To determine whether MsContactin expression by the enteric glial cells is also developmentally regulated, we immunostained embryos at progressive ages with a combination of anti-APPL, anti-GPI-Fas II, and our affinity-purified anti-MsContactin antibody (Fig. 5). During the initial spreading phase of EP cell migration, while the neurons were still on the foregut $(\sim 40-55 \mathrm{hpf})$, we found that MsContactin expression in the ENS was negligible (data not shown). In contrast, shortly after the EP cells commenced their migration onto the midgut bands (58-62 hpf), we first detected MsContactin in glial processes extending around the migratory neurons (Fig. 5 $A_{1}$ ). Once again, we found that anti-MsContactin immunoreactivity overlapped with GPI-Fas II in the glial cells (Fig. $5 A_{2}$, green) that ensheathed the migratory neurons (expressing 

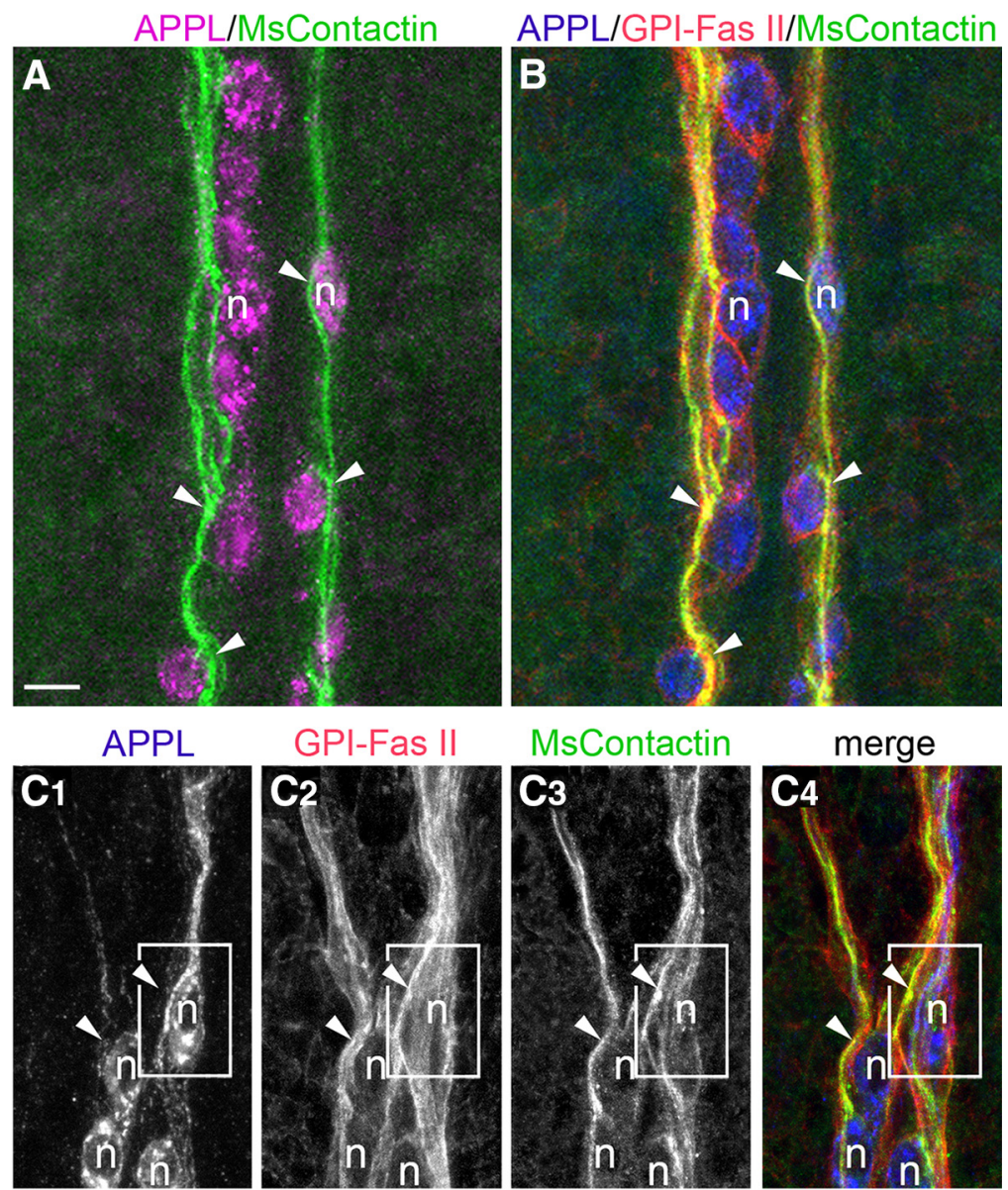

GPI-Fas II

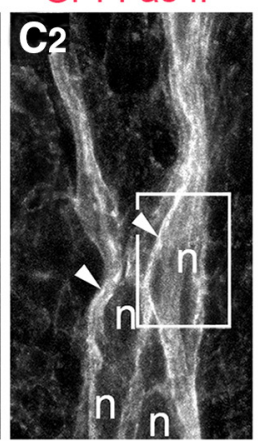

MsContactin
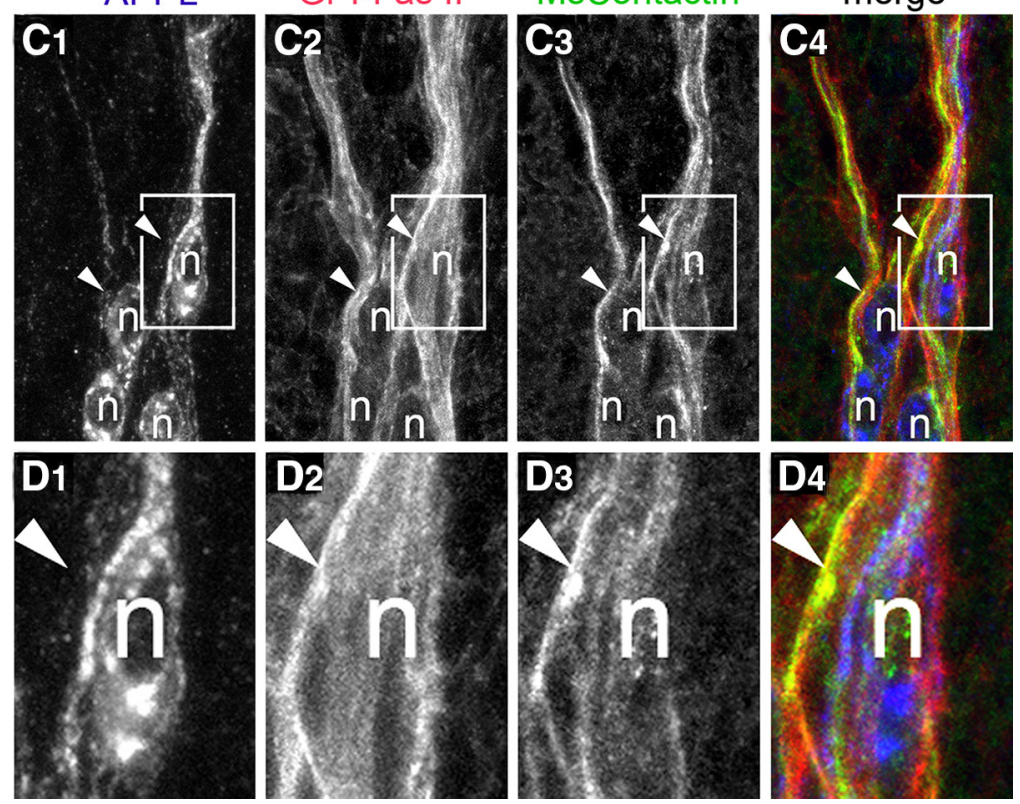

Figure 4. APPL is expressed by migratory EP cells while MsContactin is expressed by ensheathing glial cells on the midgut band pathways. A, Mid-dorsal muscle bands of an embryo (at 65 hpf) immunostained with anti-cAPPL (magenta) and MsContactin (green). Only the EP cells express APPL, while the ensheathing glial cells express MsContactin. B, Same preparation counterstained with anti-GPI-Fas II (red); GPI-Fas II immunoreactivity overlaps with MsContactin (green) but is more widely distributed throughout the glial processes (anti-APPL shown in blue). Arrowheads indicate regions of strong colocalization of MsContactin with GPI-Fas II in glial processes, adjacent to a neuron (n) expressing APPL. C, Higher-magnification view of the ENS in an older embryo (75 hpf) that was triple-immunostained with anti-APPL $\left(\boldsymbol{C}_{7}\right)$, anti-GPI-Fas II $\left(\boldsymbol{C}_{2}\right)$, and anti-MsContactin $\left(\boldsymbol{C}_{3}\right) . \boldsymbol{C}_{4}$, The merged image shows that MsContactin (green) colocalizes with GPI-Fas II (red) in the ensheathing glial processes but not with APPL (blue) in the migratory neurons. At this stage, low levels of MsContactin immunoreactivity are also apparent in midgut epithelial cells, adjacent to the muscle band pathways. $\boldsymbol{D}$, Higher-magnification view of the boxed regions indicated in $\boldsymbol{C}$. $\boldsymbol{D}_{1}$, EP cell expressing APPL is ensheathed by GPI-Fas II-positive glial cells $\left(\boldsymbol{D}_{2}\right)$. $\mathbf{D}_{3}$, MsContactin expression overlaps with GPI-Fas II in the ensheathing glial cells. $D_{4}$, Triple merge shows that MsContactin (green) colocalizes with GPI-Fas II (red), but not APPL (blue). Each panel shows compressed images from 12 optical sections. Scale bars: $\boldsymbol{A}-\boldsymbol{C}, 20 \mu \mathrm{m} ; \boldsymbol{D}, 5 \mu \mathrm{m}$.

APPL; magenta). During subsequent phases of development, MsContactin levels became progressively more robust in the glial processes ensheathing the EP cells (Fig. $5 B_{1}$ ), while APPL levels remained high in the neuronal somata and their leading processes as the neurons transitioned from migration to axon outgrowth (Fig. $5 B_{2} ; 65$ hpf). MsContactin was also detectable in tracheolar cells extending in from the lateral body wall during this period (Fig. $5 B_{1}, \mathrm{t}$ ). However, since the tracheoles do not invest the ENS until later in development ( $\sim 75 \mathrm{hpf})$, they are unlikely to influence EP cell migration and outgrowth directly. Even after APPL expression was downregulated in the fully mature neurons (Fig. $5 C_{2} ; 90 \mathrm{hpf}$ ), Ms Contactin levels remained high in the glial processes throughout the remainder of embryogenesis (Fig. $5 C_{1}$ ). These results indicate that glial MsContactin is temporally and spatially positioned to interact with neuronal APPL during key periods of migration and axon outgrowth.

\section{Glial Contactin is required for preventing ectopic neuronal migration and outgrowth}

In previous work, we demonstrated that APPL-Go $\alpha$ signaling plays an important role in regulating the guidance of the EP cells, whereby knocking down APPL expression or inhibiting Go $\alpha$ activity produced the same distinctive pattern of ectopic migration and outgrowth onto the interband regions of the midgut ( $\mathrm{Ra}$ maker et al., 2013). To investigate how MsContactin might contribute to this response, we first tested whether knocking down MsContactin expression in the glial cells also affected EP cell behavior. Synchronized embryos were opened in culture shortly before the onset of migration (50 hpf), a stage when the premigratory neurons have begun to express APPL (Swanson et al., 2005), but the proliferating glial precursor cells have not yet begun to ensheath the neurons or express MsContactin. We then treated the developing ENS in these preparations with either MsContactin-specific MOs (validated in our GV1 cell assay; Fig. 2B) or a variety of control MOs for $24 \mathrm{~h}$, spanning the periods of EP cell migration and outgrowth. The embryos were subsequently fixed and immunostained with anti-pan-Fas II antibodies to fully label the neurons, glial cells, and their processes, which we could readily distinguish by their morphologies and positions using our camera lucida-based methods (Wright et al., 1999; Coate et al., 2008).

Examples of embryos from each treatment condition are shown in Figure 6 (redrawn from camera lucida images). Figure $6 A$ shows the positions of the premigratory neurons adjacent to the foregut-midgut boundary (FG/MG) at experimental onset. Figure $6 B$ shows a preparation that was treated with control MOs for $24 \mathrm{~h}$, in which the neurons and their processes remained predominantly confined to the muscle bands. In contrast, treating embryos with MsContactin-specific MOs resulted in a striking pattern of ectopic migration and neurite outgrowth onto the interband regions (Fig. 6C, arrows). Quantification of these effects (Fig. 6E) showed that knocking down MsContactin expression 
Contactin
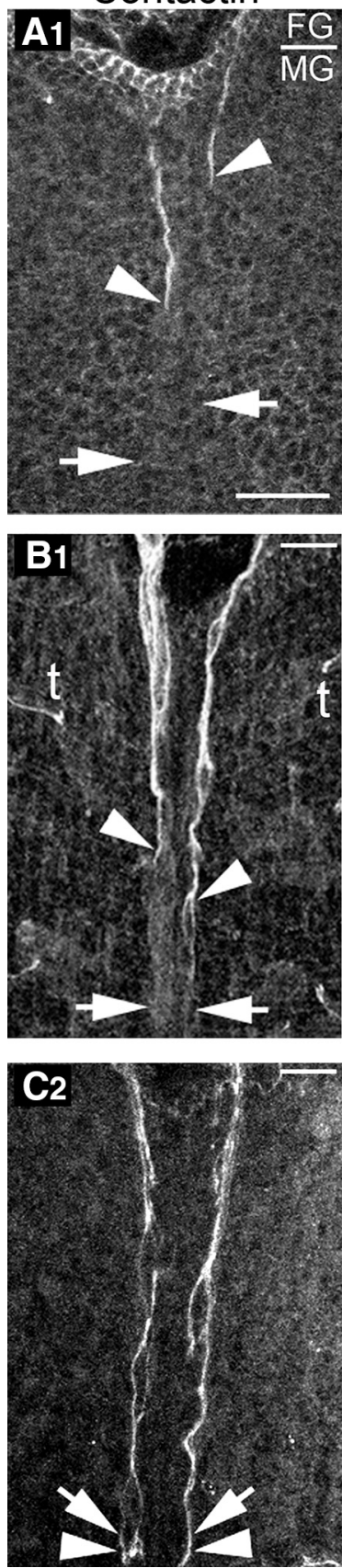
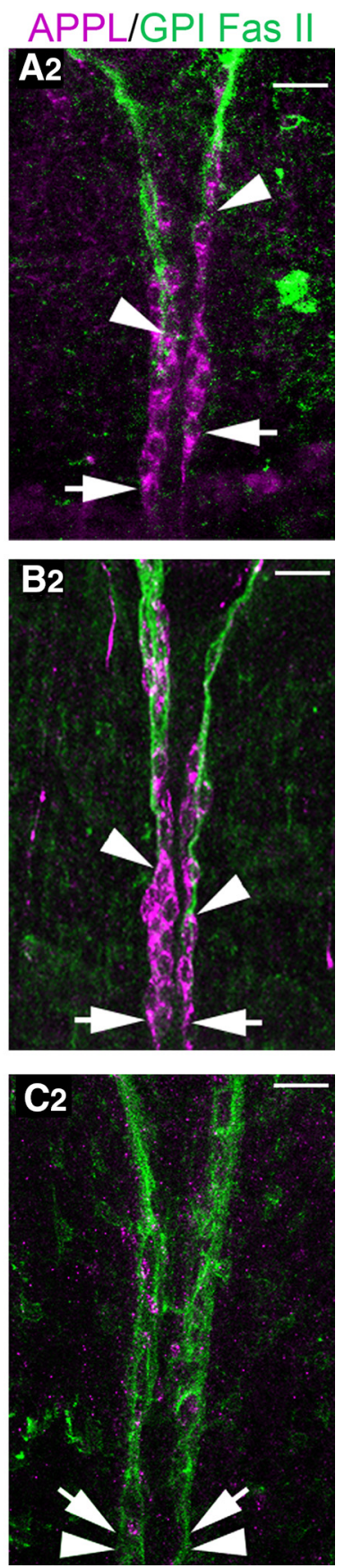

Figure 5. Developmental expression of MsContactin by enteric glial cells corresponds to their ensheathment of the migratory EP cells. Panels show the developing ENS at progressive stages of development, triple-immunostained with anti-APPL (magenta), anti-GPI-Fas II (green), and anti-MsContactin (shown separately in grayscale). Arrows indicate the extent of EP cell migration; arrowheads indicate the extent of glial spreading. Only the mid-dorsal pair of midgut band pathways is shown. $\boldsymbol{A}_{\boldsymbol{1}}, \boldsymbol{A}_{2}$, By $62 \mathrm{hpf}$, APPL-positive EP cells (magenta) have migrated $\sim 200 \mu \mathrm{m}$ posteriorly along the muscle bands while avoiding the adjacent interband muscles. Glial cells expressing GPI-Fas II (green) have begun to migrate along the pathways established by the EP cells. anti-MsContactin immunoreactivity $\left(\boldsymbol{A}_{\boldsymbol{1}}\right)$ overlaps with anti-GPI-Fas II expression $\left(\boldsymbol{A}_{2}\right)$, labeling glial processes that have begun to extend around the neuronal somata. $\boldsymbol{B}_{1}, \boldsymbol{B}_{2}$, By $65 \mathrm{hpf}$, EP cells expressing APPL have terminated their migration but continue to extend axons posteriorly along their band pathways (Fig. $1 A_{3}$ ). Glial cells coexpressing MsContactin $\left(\boldsymbol{B}_{\boldsymbol{1}}\right)$ and GPI-Fas II ( $\boldsymbol{B}_{\mathbf{2}}$; green) have continued to spread along the EP cell pathways, ensheathing the neuronal somata (magenta). $\boldsymbol{C}_{1}, \boldsymbol{C}_{2}$, By $90 \mathrm{hpf}$, the EP cells have substantially downregulated their expression of APPL, corresponding to the lateral growth of their terminal branches onto the interband musculature. The glial cells have almost completely ensheathed the neuronal somata and continue to express both MsContactin $\left(\boldsymbol{C}_{\mathbf{1}}\right)$ and GPI-Fas II $\left(\boldsymbol{C}_{2}\right)$ at robust levels. GPI-Fas II is uniformly distributed throughout the glial processes

caused a significant increase in the number of neurons (hatched bars; $p=0.003$ ) and their processes (stippled bars; $p=0.043$ ) that traveled inappropriately onto the interband regions. On average, $20 \%$ of the EP cells exhibited these behaviors in each preparation, in contrast to the small number of "arch" neurons seen in controls (Fig. 6B, open arrowheads). We also noted that most ectopic growth was exhibited by trailing groups of migratory neurons, corresponding with our observation that the ensheathing glial cells expressing MsContactin lag slightly behind the leading EP cells during normal development (Fig. 5). In contrast, knocking down MsContactin expression had no significant effect on the extent of migration and axon elongation by the leading groups of EP cells that remained on the muscle bands (Fig. 6D), which is consistent with our previous evidence that other guidance cues support the preferential guidance of the EP cells along these pathways (Wright et al., 1999; Coate et al., 2008). These results are also remarkably similar to the effects of interfering with APPL expression or Go $\alpha$ signaling, as described below.

\section{Complementary binding of APPL and Contactin fusion proteins in the developing ENS}

A variety of studies have indicated that the E1/E2 extracellular domains of APP family proteins can interact with different Contactins (Ma et al., 2008; Osterfield et al., 2008; Osterhout et al., 2015). Accordingly, we generated a fusion protein consisting of the E1/E2 domains of APPL plus human placental AP (sAPPLAP; Fig. 7A) and tested whether it could bind to MsContactin on the enteric glial cells. After treating embryos with sAPPL-AP for $90 \mathrm{~min}$, we triple-immunostained the preparations with antiAPPL, anti-GPI-Fas II, and anti-AP (to detect bound fusion proteins). When we examined the midgut regions of the enteric plexus in these preparations, we found that sAPPL-AP strongly labeled both the EP cells and the ensheathing glial cells (data not shown), which is consistent with previous reports that APP can bind homophilically to itself and heterophilically to Contactin family members (Soba et al., 2005; Osterfield et al., 2008; Tachi et al., 2010; Kaden et al., 2012). However, the close proximity of the neuronal and glial membranes on the band pathways made it difficult to differentiate between SAPPL-AP labeling on the two cell types. Instead, we again focused on the esophageal nerve of the foregut, which (as noted earlier) contains fasciculated axons ensheathed by glial cells but no neuronal somata. As shown in Figure $7 D, E$, we could readily distinguish the axon bundles (expressing APPL; magenta) from the ensheathing glia (expressing GPI-Fas II and MsContactin; green), recapitulating the cell typespecific expression of these proteins in the midgut ENS. Accordingly, we focused on this region to test whether glial MsContactin specifically binds APPL.

For this assay, we pretreated cultured embryos with either control MOs or MOs targeting MsContactin mRNA for $24 \mathrm{~h}$, and then labeled the preparations with sAPPL-AP before counterstaining with neuronal and glial markers. In preparations treated with control MOs (Fig. 7C), we found that sAPPL-AP (Fig. $7 C_{3}$ ) robustly labeled both the axons within the esophageal nerve expressing APPL (Fig. $7 C_{1}$, arrows) and the surrounding glial cell membranes expressing GPI-Fas II (Fig. $7 C_{2}$, arrowheads). No detectable signal was seen in preparations labeled with control AP

surrounding the neuronal somata, whereas MsContactin immunoreactivity appears more intense in some glial processes than others. FG/MG, Foregut-midgut boundary. Scale bar, $40 \mu \mathrm{m}$. 

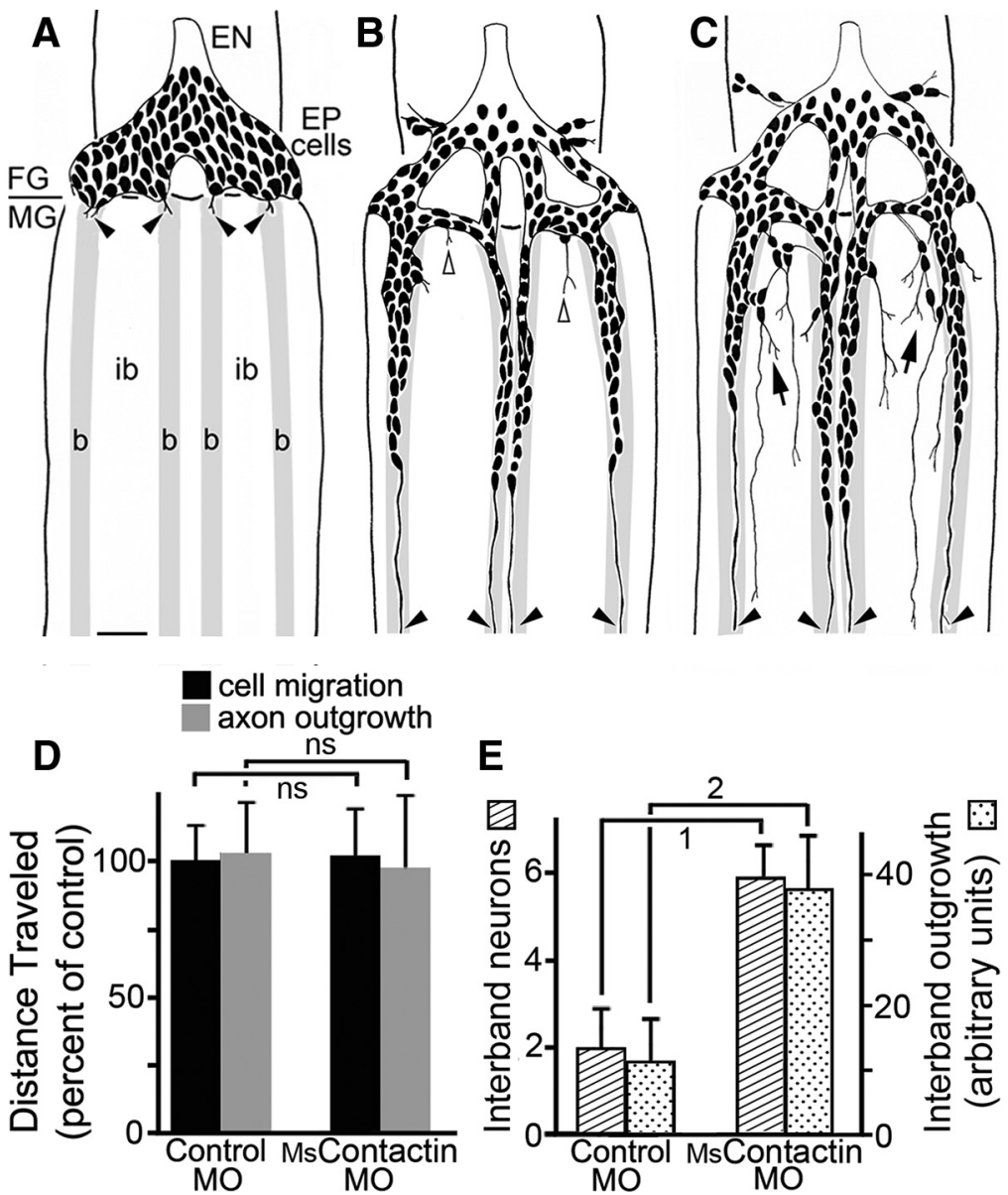

Figure 6. Inhibiting MsContactin expression in the developing ENS permits ectopic migration and outgrowth by the EP cells $\boldsymbol{A}-\boldsymbol{C}$, Examples of the developing ENS in cultured embryos fixed and immunostained with anti-pan Fas II antibodies (panels were redrawn from camera lucida images). $\boldsymbol{A}$, Preparation fixed and immunostained at experimental onset ( $\sim 50 \mathrm{hpf}$ ); at this stage, the EP cells had spread bilaterally around the foregut, and subsets of the premigratory neurons had begun to align with the midgut muscle bands (b) but not the interband regions (ib). Arrowheads indicate the leading EP cell processes on each midgut muscle band (only the 4 dorsal bands are shown). B. Preparation treated with control MOs and cultured for $24 \mathrm{~h}$ (through the periods of migration and axon outgrowth). The EP cells and their axons remained predominantly confined to the band pathways; only a few neurons extended minor processes onto the interband regions, including two EP cells in the arch nerves between adjacent bands (open arrowheads). C, Preparation treated with MsContactin-specific MOs that had been previously validated in GV1 cells (Fig. 2B); a substantial number of EP cells migrated and elaborated processes onto the interband regions of the midgut, although EP cell migration and outgrowth along the bands were similar to those of controls. FG/MG, Foregut-midgut boundary; EN, esophageal nerve of the foregut. Scale bar, $40 \mu \mathrm{m}$. D. The overall extent of migration (black bars) and axon outgrowth (gray bars) by neurons that remained on the band pathways was not significantly different in preparations treated with control MOs or MsContactinspecific M0s; distances were normalized to untreated and vehicle-treated controls in each experiment. $N \geq 16$ for each condition. Histogram indicates means \pm SD. $\boldsymbol{E}$, The number of neurons (hatched bars) and the extent of processes (stippled bars) that traveled onto the interband regions were significantly increased in preparations treated with MsContactin-specific M0s, compared with controls. The extent of interband outgrowth was normalized to the diameter of the midgut in each preparation to accommodate for variations caused by fixation and immunohistochemical processing (typically $<10 \%$ of average diameters in each experiment). For neuronal migration, $t_{(54)}=0.480$; for axon outgrowth, $t_{(54)}=0.299$; for the number of interband neurons, $t_{(12)}=$ 3.66 ; for the extent of interband outgrowth, $t_{(12)}=2.26$. Histogram indicates means \pm SEM. $1, p=0.003 ; 2, p=0.043$.

proteins or medium alone (Fig. $7 B$ ). In contrast, when we pretreated embryos with MsContactin-specific MOs (Fig. $7 F$ ), we found that SAPPL-AP labeling on the glial membranes was dramatically reduced (Fig. $7 F_{3}$, arrowheads), whereas there was no detectable effect on APPL expression by the axons (Fig. $7 F_{1}$ ) or GPI-Fas II expression by the glial cells (Fig. $7 F_{2}$ ). In addition, treatment with MsContactin MOs had no consistent effect on axonal labeling by sAPPL-AP (Fig. $7 F_{3}$, arrows). These experiments indicate that the enteric glial cells require MsContactin to bind APPL, supporting the model that glial MsContactin might function as a ligand for neuronal APPL within the developing ENS.
As a complementary strategy, we also tested whether fusion proteins derived from MsContactin could bind APPL on the migratory EP cells. Whereas Contactins can bind homophilically via their Ig domains (Freigang et al., 2000; Mörtl et al., 2007), both Contactin-3 and Contactin- 4 have been shown to bind specifically to the extracellular domains of APP family proteins via their FN-III domains (Osterfield et al., 2008). Accordingly, we generated a soluble fusion protein consisting of the four FN-III domains of MsContactin plus human $\mathrm{Fc}$ (MsCont-Fc; Fig. 7G). We then treated cultured embryos for $24 \mathrm{~h}$ with control MOs or MOs targeting APPL mRNA (validated in our GV1 cell assays; Fig. 2). The preparations were subsequently labeled with MsCont-Fc for $90 \mathrm{~min}$, and counterstained with anti-APPL (to label the EP cells) plus anti-Fc (to detect bound MsCont-Fc).

For this analysis, we focused on leading groups of EP cells that had not yet been fully ensheathed by the enteric glia, thereby avoiding potential interactions with glial MsContactin. As shown in Figure $7 \mathrm{H}, \mathrm{I}$, when embryos were pretreated with control MOs, the EP cells continued to express APPL at high levels (Fig. $\left.7 H_{1}, I_{1}\right)$. Subsequent incubation of these preparations with MsCont-Fc fusion proteins robustly labeled the neurons and their processes (detected with anti-Fc; Fig. $7 I_{2}$ ), whereas incubation with defined saline alone produced no appreciable anti-Fc staining (Fig. $7 \mathrm{H}_{2}$ ). In contrast, when embryos were treated with APPLspecific MOs (Fig. 7J), we found that expression of APPL in the EP cells (Fig. $7 J_{1}$ ) and labeling with MsCont-Fc (Fig. $7 J_{2}$ ) were both substantially reduced. Quantification of these results (Table 1) showed that treatment with APPL-specific MOs caused a significant loss of APPL expression and MsCont-Fc binding to the neurons, compared with preparations treated with control MOs. Together, these experiments indicate that enteric glial cells require MsContactin to bind APPL while the migratory EP cells require APPL to bind MsContactin, supporting the model that MsContactin might function as a ligand for APPL within the developing ENS.

It has been postulated that an authentic APP ligand might stimulate the proteolytic cleavage of the holoprotein by one or more secretases (O'Brien and Wong, 2011; Zheng and Koo, 2011). Accordingly, we also tested whether treating embryos with MsCont-Fc altered the relative abundance of full-length or cleaved forms of APPL (quantified by our Western blotting methods). However, these experiments yielded ambiguous results: in some experiments, we found that MsCont-Fc treatment moderately increased the generation of APPL-derived fragments, 

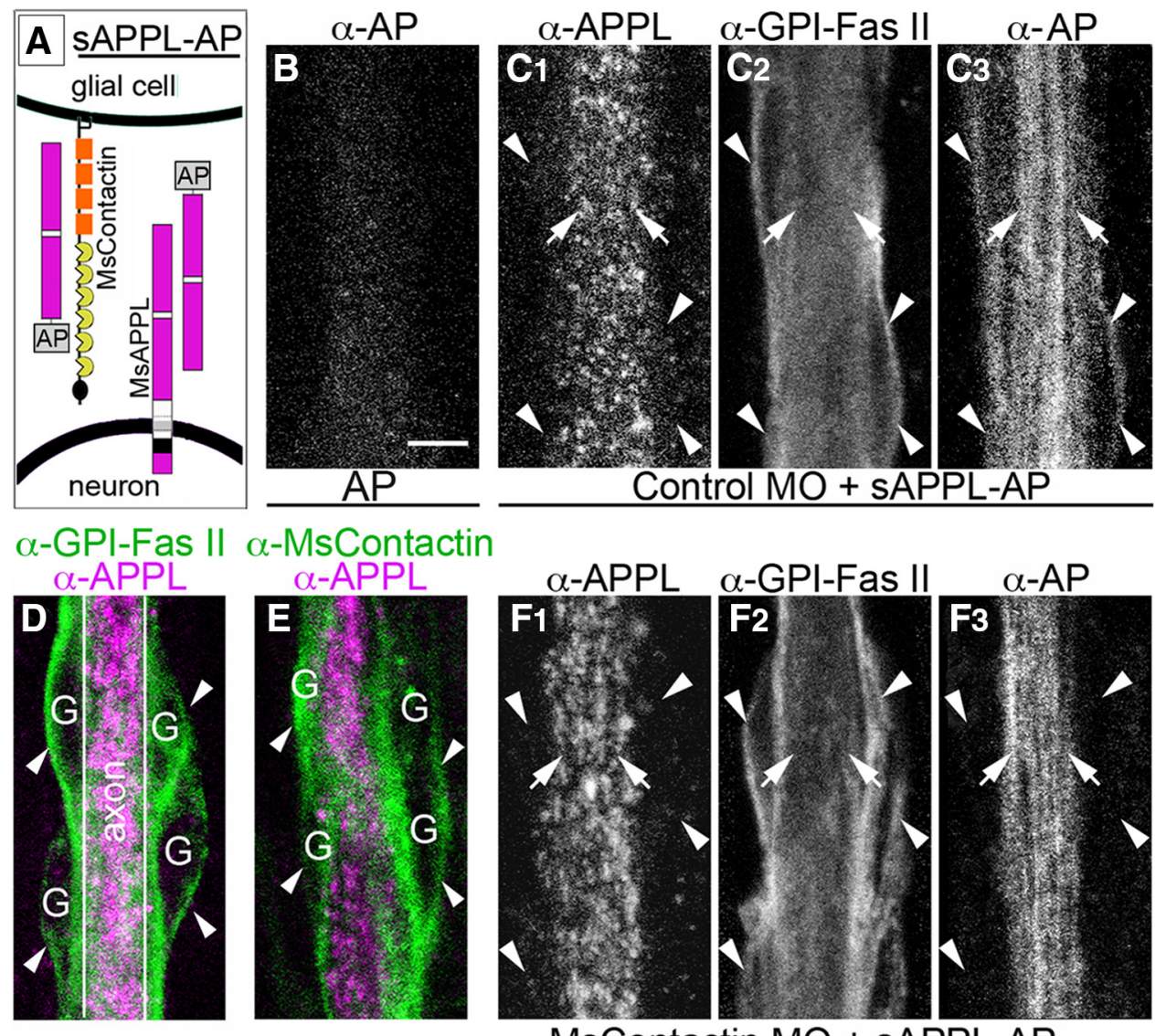

MsContactin MO + SAPPL-AP
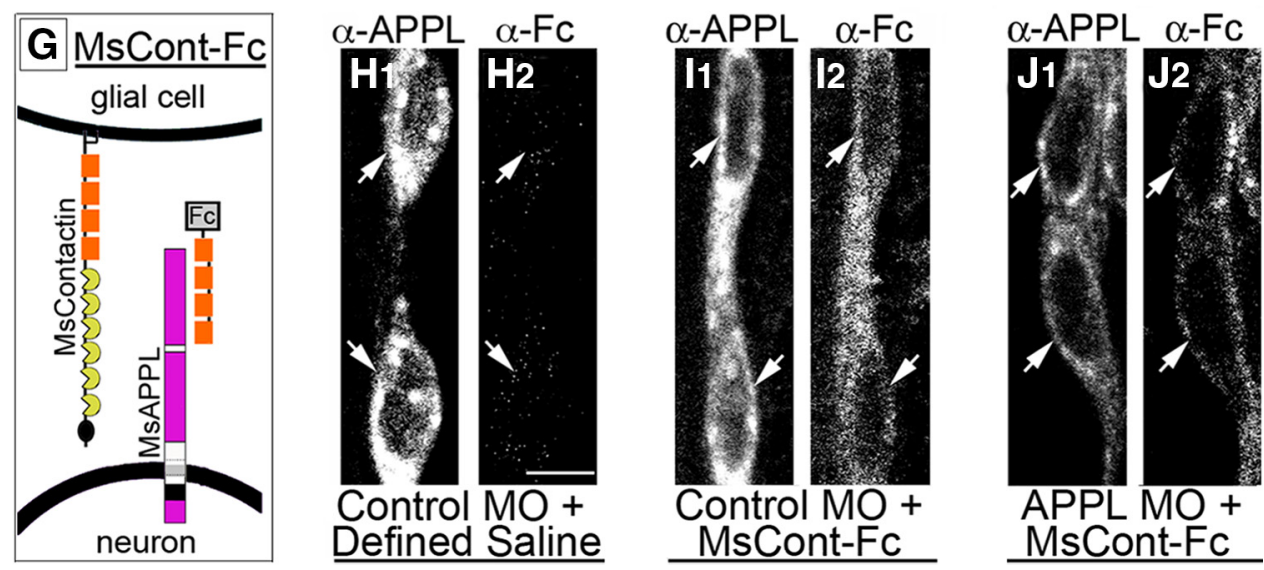

Figure 7. APPL and MsContactin fusion proteins bind complementary cell types in the developing ENS. A, Schematic representation of labeling experiments using soluble ectodomain fragments of APPL (E1/E2 domains) fused to AP (sAPPL-AP). Based on work in other models, SAPPL-AP might bind full-length APPL on neurons and/or MsContactin on glial cells. $\boldsymbol{B}-\boldsymbol{F}$, Images of the esophageal nerve on the foregut of embryos at $65 \mathrm{hpf}$ (images collected just anterior to the enteric plexus containing the EP cell bodies; Fig. 1A). Each panel consists of a compressed stack of three sequential $0.2 \mu \mathrm{m}$ optical sections. Images of anti-AP immunoreactivity in $\boldsymbol{B}, \boldsymbol{C}$, and $\boldsymbol{F}$ were acquired using identical laser settings in all experimental preparations. $\boldsymbol{B}$, Embryo incubated with control AP protein and labeled with anti-AP shows only low background levels of immunoreactivity. C, Embryo treated with control MOs for $24 \mathrm{~h}$, then incubated with sAPPL-AP and subsequently immunostained with anti-APPL $\left(\boldsymbol{C}_{\mathbf{7}}\right)$, anti-GPI-Fas II $\left(\boldsymbol{C}_{2}\right)$, and anti-AP to detect bound SAPPL-AP $\left(\boldsymbol{C}_{3}\right)$. Arrows in $\boldsymbol{C}$ indicate fasciculated axons expressing APPL (originating from midgut EP cells and frontal ganglion neurons on the anterior foregut); arrowheads indicate ensheathing glial cells expressing GPI-Fas II. Detectable sAPPL-AP labeling ( $\boldsymbol{C}_{3}$ ) was visible on both the axon fascicles (arrows) and surrounding glial cells (arrowheads). D, Esophageal nerve immunostained with anti-APPL (expressed by axons) and anti-GPI-Fas II [expressed by glial cells (G)]. E, Esophageal nerve immunostained with anti-APPL and anti-MsContactin (also expressed by the glial cells). $\boldsymbol{F}$, Embryo treated with MsContactin-specific MOs for $24 \mathrm{~h}$, then incubated with sAPPL-AP and subsequently immunostained with anti-APPL $\left(\boldsymbol{F}_{1}\right)$, anti-GPI-Fas II $\left(\boldsymbol{F}_{2}\right)$, and anti-AP $\left(\boldsymbol{F}_{3}\right)$. Glial labeling by sAPPL-AP was substantially reduced following treatment with MsContactin MOs $\left(\boldsymbol{F}_{3}\right.$, arrowheads) compared with treatment with control MOs ( $\boldsymbol{C}_{3}$, arrowheads), whereas axonal labeling was unaffected (arrows). $\mathbf{G}$, Schematic representation of labeling experiments using soluble ectodomain fragments of MsContactin (FN-III domains) fused to human Fc (MsCont-Fc). Based on work in other models, MsCont-Fc might bind APPL on neurons and/or MsContactin on glial cells. H-J, Highlighted images of the leading EP cells (posterior to the ensheathing glial cells) on the mid-dorsal muscle bands of embryos at 65 hpf. Anti-APPL and anti-Fc immunoreactivity was imaged using identical laser settings for each fluorochrome in all experimental preparations. $\boldsymbol{H}$, Embryo treated with control MOs for $24 \mathrm{~h}$, then incubated with defined saline and immunostained with anti-APPL $\left(\boldsymbol{H}_{\mathbf{1}}\right)$ and anti-Fc $\left(\boldsymbol{H}_{2}\right) . \boldsymbol{I}$, Embryo treated with control MOs for $24 \mathrm{~h}$, then incubated with MsCont-Fc and subsequently immunostained with anti-APPL $\left(\boldsymbol{I}_{\mathbf{1}}\right)$ and anti-Fc $\left(\boldsymbol{I}_{2} ;\right.$ to detect bound MsCont-Fc).J, Embryo that was treated with APPL-specific MOs for $24 \mathrm{~h}$, then incubated with MsCont-Fc and subsequently immunostained with anti-APPL $\left(J_{7}\right)$ and anti-Fc $\left(J_{2}\right)$. EP cell labeling with MsCont-Fc was substantially reduced following treatment with APPL-specific MOs, compared with control MOs. Scale bar $=10 \mu \mathrm{m}$. 
Table 1. MsCont-Fc fusion proteins bind to EP cells in an APPL-dependent manner ${ }^{a}$

\begin{tabular}{lll}
\hline & \multicolumn{2}{l}{ Fluorescent intensity (arbitrary units) } \\
\cline { 2 - 3 } Treatment conditions & Anti-APPL $(p=0.0015)$ & $\operatorname{Anti-Fc}(p=0.0033)$ \\
\hline Control M0 & $138 \pm 34$ & $127 \pm 25$ \\
APPL M0 & $85 \pm 6$ & $55 \pm 46$ \\
\hline
\end{tabular}

${ }^{a}$ Quantification of APPL expression levels and MsCont-Fc labeling in EP cells of Manduca embryos treated with control MOs or APPL-specific MOs (Fig. 7). Incubation with APPL-specific MOs significantly reduced both the relative levels of anti-APPL and anti-Fc immunoreactivity (detecting bound MsCont-Fc). Each data set shows mean \pm SD; $N=7$ per condition. Statistical significance was calculated using Student's two-tailed $t$ test. For relative APPL levels: $t_{(12)}=4.1 ;$ anti-Fc: $t_{(12)}=3.7$.

while in other replicate assays, we observed either no change or a moderate reduction in APPL processing (data not shown). Curiously, several other investigations exploring this issue have also produced conflicting findings. Under some conditions, both Contactin-1 (F3) and Contactin-2 (TAG-1) enhanced APP processing (Ma et al., 2008; Puzzo et al., 2015), whereas in different assays, Contactin-2 had no effect (Rice et al., 2013), and Contactin-4 fusion proteins were found to have variable effects on APP cleavage, depending in part on holoprotein expression levels (Osterfield et al., 2008). Additional studies will therefore be needed to address whether MsContactin-APPL signaling regulates APPL processing in the developing ENS, which might provide an important mechanism for terminating APPL-dependent responses in the migratory neurons.

\section{MsContactin regulates APPL-dependent migration and outgrowth in the nervous system}

Since APPL-Go $\alpha$ signaling normally restricts the EP cells from traveling inappropriately off their muscle band pathways (Ramaker et al., 2013), we postulated that overstimulating this response with MsContactin fusion proteins should cause a more global inhibition of their migration and outgrowth, similar to the effects of hyperactivating Go $\alpha$. Accordingly, we treated the premigratory EP cells of cultured embryos at $50 \mathrm{hpf}$ (before the onset of MsContactin expression) with different combinations of MOs and fusion proteins (Fig. 8A), and then subsequently analyzed the extent of EP cell migration and outgrowth on both the bands and interband regions after $24 \mathrm{~h}$ of subsequent development. In untreated preparations and preparations treated with control reagents, we found that the neurons remained primarily confined to their band pathways (Fig. $8 B$ ), similar to our earlier experiments. In contrast, treating the EP cells with MsCont-Fc resulted in a dramatic reduction in the distance of their migration and axon outgrowth along the bands (Fig. $8 C$ ), matching the effects of hyperactivating APPL-Go $\alpha$ signaling by other methods (Ramaker et al., 2013). To test whether this effect was APPLdependent, we first verified that treatment with APPL MOs caused a marked increase in ectopic migration and outgrowth (Fig. 8D, arrows), similar to the effects of knocking down MsContactin expression (Fig. 6C). Notably, when APPL expression was initially inhibited by this method, subsequent treatment with MsCont-Fc no longer stalled EP cell motility: the overall extent of migration and outgrowth was largely restored in these preparations (compared with controls), accompanied by a moderate increase in ectopic growth onto the interband regions (Fig. $8 E$, arrows).

These results are also summarized in Figure $8 F-H$. Consistent with our earlier studies, treatment with APPL-specific MOs (plus control medium) had no effect on the normal extent of neuronal migration and axon outgrowth along the muscle band pathways (Fig. 8F). However, knocking down APPL expression did cause a significant increase in ectopic migration (Fig. $8 G$ ) and outgrowth
(Fig. $8 \mathrm{H}$ ) onto the interband regions, compared with controls. This response is analogous to the effects of knocking out all three APP family proteins (APP, APLP1, and APLP2) in transgenic mice, which resulted in a striking pattern of ectopic neuronal migration and cortical heterotopias (Herms et al., 2004). In contrast, treatment with MsCont-Fc (plus control MOs) significantly reduced the overall extent of normal migration and outgrowth along the band pathways (Fig. $8 F$ ), while this effect was largely prevented by pretreatment with APPL MOs. Notably, preparations in this latter group also exhibited a significant increase in interband migration (Fig. 8G) and a more moderate increase in ectopic outgrowth (Fig. $8 \mathrm{H}$ ) compared with controls, although this effect was not as dramatic as in preparations treated with APPL MOs alone.

Last, based on our previous evidence that APPL regulates neuronal migration in a Go $\alpha$-dependent manner, we also tested whether the effects of MsCont-Fc treatment were blocked by PTX, which in insect systems specifically inhibits Go $\alpha$ but not Gi $\alpha$ (Thambi et al., 1989). For this experiment, we treated the EP cells of cultured embryos just before the onset of migration $(\sim 52$ hpf; Fig. 9A), a stage when the neurons had begun to express APPL but shortly before the onset of MsContactin expression by the glial cells, and then, using our camera lucida-based methods, analyzed them after $24 \mathrm{~h}$ of subsequent development. Similar to the results shown in Figure 8, we found that treating cultured embryos with MsCont-Fc caused a significant inhibition of migration and outgrowth along the band pathways (Fig. 9C), and also prevented the sparse interband outgrowth seen in control preparations (Fig. 9B, open arrowheads). In contrast, treatment with PTX plus MsCont-Fc overcame the inhibitory effects of MsCont-Fc alone, resulting in a dramatic increase in the number of neurons and processes that traveled into the interband regions (Fig. 9D), as well as enhancing migration and outgrowth along the band pathways. These effects were similar to the responses seen in preparations treated with PTX alone (Fig. 9E), recapitulating our earlier studies showing that inhibiting Go activity increases the extent of outgrowth on both the bands and interband regions (Ramaker et al., 2013).

These results are also summarized graphically in Figure $9 F, G$ : treatment with MsCont-Fc significantly reduced the extent of normal migration and outgrowth along the bands (Fig. 9F) and moderately reduced the low basal levels of interband growth seen in control preparations (Fig. 9G). In contrast, treatment with MsCont-Fc plus PTX (or PTX alone) had the opposite effect, significantly enhancing the extent of normal migration and axon elongation along the bands (Fig. $9 F$ ) while dramatically increasing ectopic growth and migration onto the interband regions (Fig. 9G). The higher baseline levels of ectopic growth shown in Figure 9 correspond with the fact that our assays using PTX were initiated at a slightly later developmental time than the experiments shown in Figures 6 and 8. Because embryos grown in our culture conditions do not survive as larvae, we could not directly assess the functional consequences of this aberrant neuronal migration and outgrowth on gut physiology. However, in previous work, we documented abnormal midgut morphologies and gut contractility in late-stage embryos with ectopic outgrowth caused by altering Go $\alpha$ activity (Horgan and Copenhaver, 1998), suggesting that perturbing normal APPL-MsContactin signaling should have similar deleterious consequences. In combination, these experiments augment our previous evidence that APPL functions as a neuronal guidance receptor in the EP cells, and indicate that MsContactin serves as an endogenous ligand capable of activating APPL-dependent responses within the develop- 

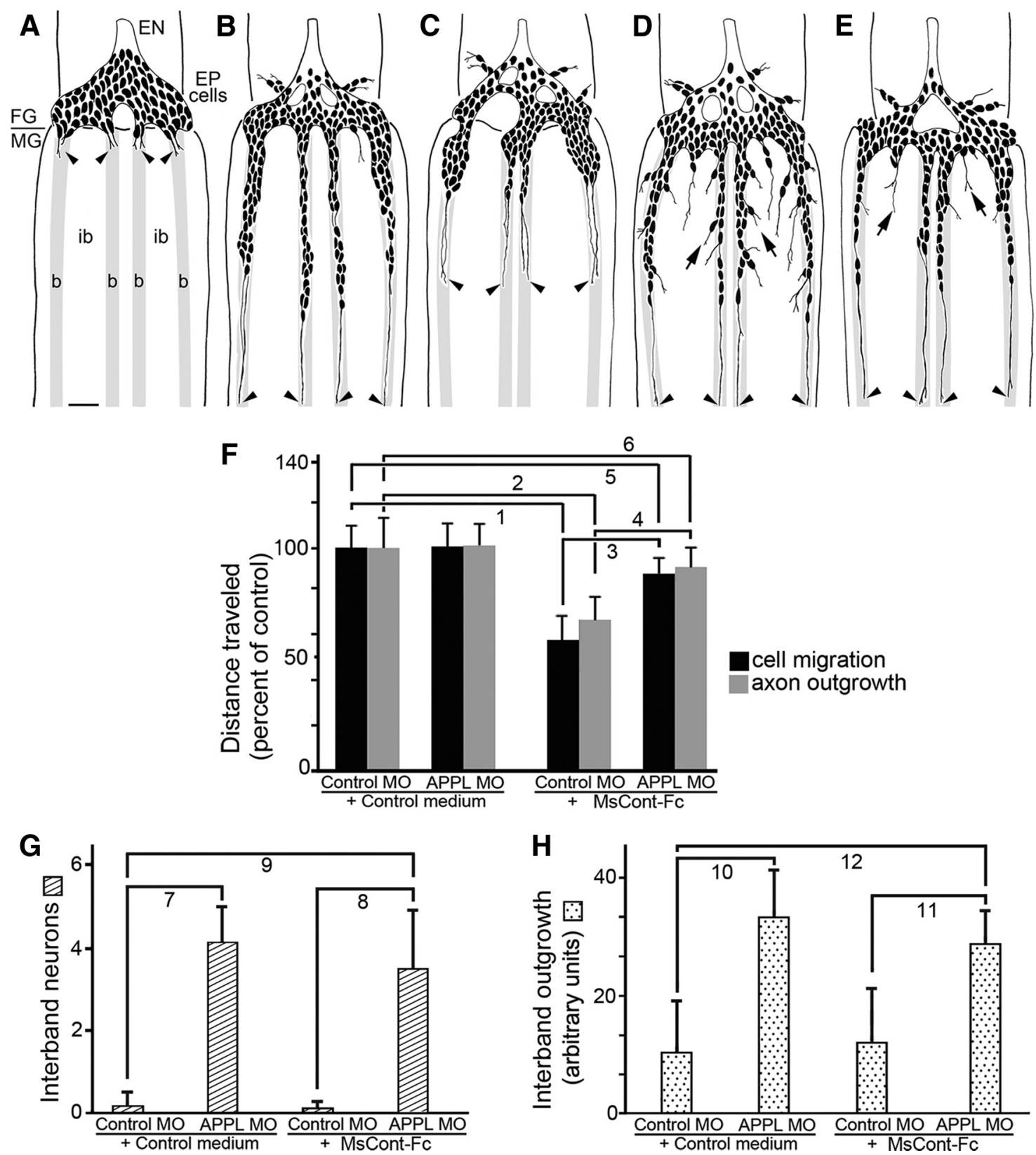

Figure 8. Soluble MsContactin fusion proteins inhibit EP cell migration in an APPL-dependent manner. $A-E$, Examples of the developing ENS in cultured embryos immunostained with anti-pan Fas II (redrawn from camera lucida images). FG/MG, Foregut-midgut boundary; EN, esophageal nerve on the foregut. Arrowheads indicate the leading EP cell processes on each midgut band pathway; only the four dorsal pathways are shown. Scale bar, $40 \mu \mathrm{m}$. A, Preparation fixed and immunostained at experimental onset ( $\sim 50 \mathrm{hpf}$ ); at this stage, EP cells had begun to align with the muscle bands (b) while avoiding the interband regions (ib). $\boldsymbol{B}$, Embryo treated with control MOs for $24 \mathrm{~h}$ before fixation and immunostaining; the migratory EP cells and their axons remained largely confined to the band pathways. C, Embryo treated with MsCont-Fc fusion proteins; neuronal migration and axon outgrowth were markedly reduced, compared with controls. D, Embryo treated with APPL-specific MOs; a substantial number of EP cells migrated and elaborated processes onto the interband regions of the midgut (arrows), similar to preparations treated with MsContactin-specific MOs (Fig. 6). E, Embryo treated with a combination of APPL-specific MOs plus MsCont-Fc fusion proteins. The overall extent of EP cell migration and axon elongation was similar to control preparations, accompanied by a moderate increase in ectopic migration and outgrowth onto the interband regions (arrows). $\boldsymbol{F}$, Quantification of the overall extent of migration (black bars) and axon outgrowth (gray bars) on the band pathways; distances were normalized to untreated and vehicle-treated controls in each experiment. The distance traveled by the EP cells along the bands was not affected by APPL-specific MOs (compared with controls) but was significantly reduced in preparations treated with MsCont-Fc fusion proteins. In embryos treated with a combination of APPL-specific MOs plus MsCont-Fc, migration and outgrowth distances were largely restored to control levels. For the extent of neuronal migration, $F_{(3,63)}=72.8, p<0.001$; for the extent of axon outgrowth, $F_{(3,62)}=33.0, p<0.001$. $N \geq 11$ for each condition; histograms indicate means \pm SD. $\mathbf{G}, \boldsymbol{H}$, The number of neurons ( $\boldsymbol{G}$, hatched bars) and the extent of processes ( $\boldsymbol{H}$, stippled bars) that grew into the interband regions were significantly increased by treatment with APPL-specific MOs, compared with control MOs. Treating embryos with control MOs plus MsCont-Fc did not alter the low levels of interband growth seen in untreated embryos, whereas treatment with APPL-specific MOs plus MsCont-Fc induced a significant increase in the number of ectopic neurons $(\boldsymbol{G})$ and a more moderate increase in ectopic outgrowth $(\boldsymbol{H})$; histograms indicate means \pm SD. For the number of interband neurons, $F_{(3,14)}=17.0, p<0.001$; for the extent of interband outgrowth, $F_{(3,14)}=7.2, p=0.004$. With Bonferroni's corrections, $p$ values are as follows: $1: t_{(34)}=11.7, p<0.001^{*} ; 2: t_{(34)}=8.1, p<0.001^{*} ; 3: t_{(30)}=8.0, p<0.001^{*} ; 4: t_{(29)}=4.7, p<0.001^{*} ; 5: t_{(26)}=3.6, p=$ $0.004^{*} ; 6: t_{(25)}=2.3, p=0.087 ; 7: t_{(7)}=4.9, p=0.005^{*} ; 8: t_{(7)}=5.0, p=0.005^{*} ; 9: t_{(6)}=4.4, p=0.014^{*} ; 10: t_{(7)}=4.0, p=0.015^{*} ; 11: t_{(6)}=3.2, p=0.055 ; 12: t_{(14)}=2.6$, $p=0.063 .^{*}$, Student's $t$ test results that are significant at the $\alpha=0.05$ level. 

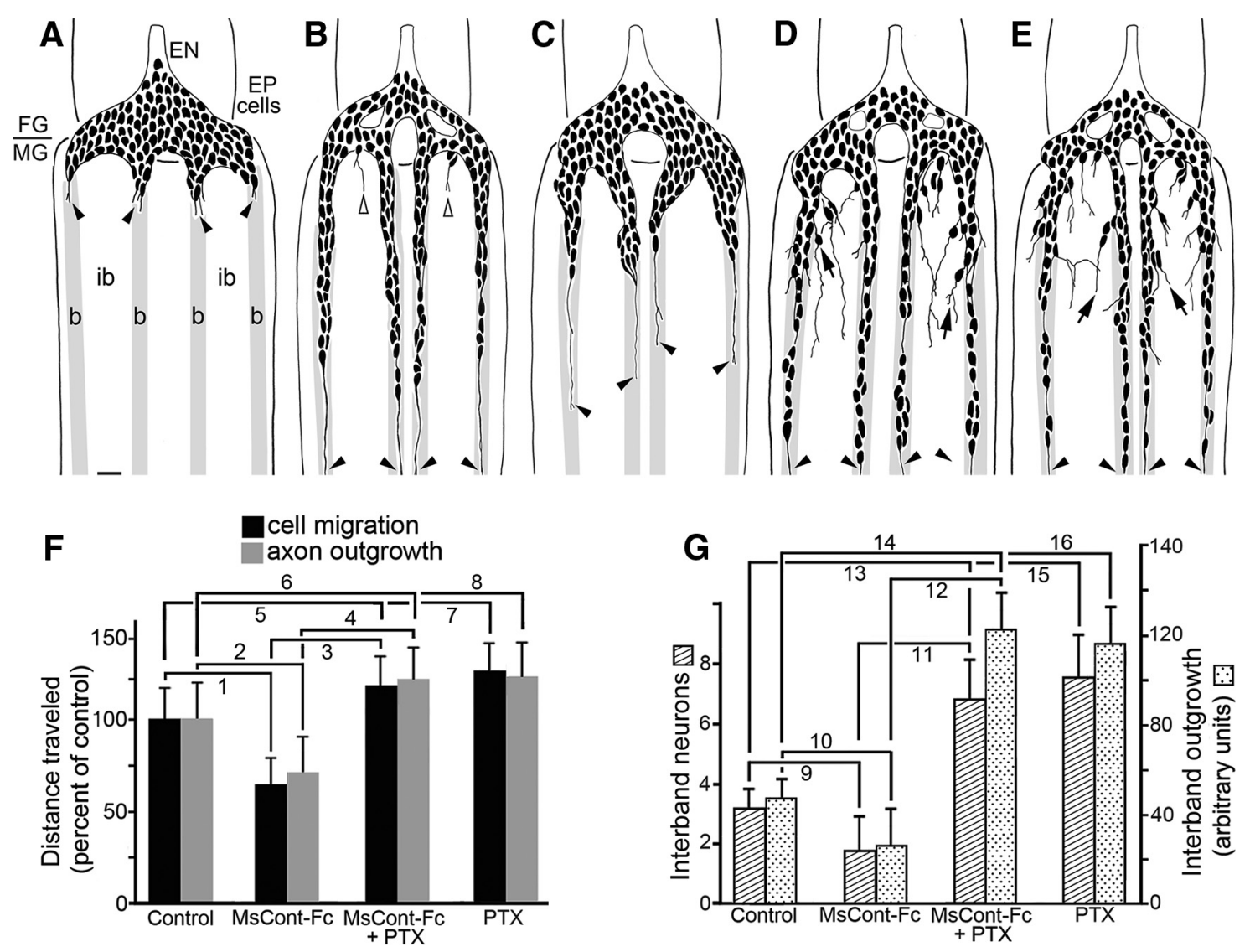

Figure 9. The effects of MsCont-Fc on neuronal migration are $G 0 \alpha$-dependent. $\boldsymbol{A}-\boldsymbol{E}$, Examples of the developing ENS in cultured embryos immunostained with anti-pan Fas II (labeling similar to Fig. 8). Arrowheads indicate the leading EP cell processes on each midgut band pathway; only the four dorsal pathways are shown. Scale bar $=40 \mu \mathrm{m}$. $A$, Preparation at experimental onset $(\sim 52$ hpf). $\boldsymbol{B}$, In cultured control embryos, the migratory EP cells and their axons remained largely confined to the band pathways (b) while avoiding the interbands (ib). $\boldsymbol{C}$, Embryo treated with MsCont-Fc fusion proteins; migration and axon outgrowth were markedly reduced, compared with controls. D, Embryo treated with a combination of MsCont-Fc and PTX to inhibit Go $\alpha$ activity; the overall extent of migration and axon outgrowth was restored to control levels, and a substantial number of neurons migrated and elaborated processes onto the interband regions (arrows). $\boldsymbol{E}$, Embryo treated with PTX alone exhibited a similar pattern of migration and outgrowth on both the bands and interband regions as seen in D.F, Quantification of the extent of EP cell migration (black bars) and axon outgrowth along the bands (normalized to control preparations in each experiment). Treatment with MsCont-Fc fusion proteins significantly reduced the total distance of migration and outgrowth (similar to Fig. 8F). In contrast, treatment with MsCont-Fc plus PTX produced a significant increase in migration and outgrowth along the bands compared with controls. Histograms indicate means $\pm S D ; N \geq 20$ for each condition. For the extent of neuronal migration, $F_{(3,150)}=74.5, p<0.001$; for the extent of axon outgrowth, $F_{(3,149)}=40.9, p<0.001$. G, Quantification of the number of neurons (hatched bars) and the extent of their processes (stippled bars) that traveled onto the interband regions. Treatment with MsCont-Fc caused a moderate reduction in the relatively small amount of interband migration and outgrowth seen in control preparations. In contrast, treatment with MsCont-Fc plus PTX caused a dramatic increase in ectopic migration and outgrowth, similar to the effects of PTX alone. For the number of interband neurons, $F_{(3,31)}=7.3, p<0.001$; for the extent of interband outgrowth, $F_{(3,31)}=65.1, p<0.001$. With Bonferroni's corrections, $p$ values are as follows: $1: t_{(96)}=8.6, p<0.001^{*} ; 2: t_{(96)}=5.8, p<0.001^{*} ; 3: t_{(57)}=14.0, p<0.001^{*} ; 4: t_{(56)}=11.6, p<0.001^{*} ; 5: t_{(101)}=5.8, p<0.001^{*} ; 6: t_{(100)}=5.1, p<$ $0.001^{*} ; 7: t_{(93)}=6.8, p<0.001^{*} ; 8: t_{(93)}=4.8, p<0.001^{*} ; 9: t_{(13)}=2.6, p=0.085 ; 10: t_{(13)}=2.3, p=0.159 ; 11: t_{(13)}=3.4, p=0.019^{*} ; 12: t_{(13)}=9.5, p<0.001^{*} ; 13: t_{(14)}=2.3, p=$ $0.172 ; 14: t_{(14)}=10.3, p<0.001^{*} ; 15: t_{(18)}=2.8, p=0.045^{*} ; 16: t_{(18)}=9.8, p<0.001^{*}{ }^{*}$, Student's $t$ test results that are significant at the $\alpha=0.05$ level.

ing ENS. Our results also support the model (Fig. 10) that glial MsContactin normally restricts ectopic migration and outgrowth via the local activation of APPL and its downstream effectors, including Go $\alpha$ (as discussed below).

\section{Discussion}

MsContactin as a candidate ligand for APPL in the developing ENS

In previous work, we demonstrated that APPL colocalizes with Go $\alpha$ in the growth cones and leading processes of the migratory EP cells, and that APPL directly interacts with Go $\alpha$ both in vitro and in vivo (Swanson et al., 2005; Ramaker et al., 2013). We also showed that inhibiting APPL-Go $\alpha$ signaling in the EP cells induced ectopic migration and outgrowth, whereas activating Go $\alpha$ inhibited their motile behavior (Horgan et al., 1995; Ramaker et al., 2013). Based on our earlier studies showing that Go $\alpha$ activation in the EP cells induces voltage-independent $\mathrm{Ca}^{2+}$ influx (Horgan and Copenhaver, 1998), these results suggested that
APPL-Go $\alpha$ signaling promotes $\mathrm{Ca}^{2+}$-dependent retraction responses to local guidance cues encountered by the migratory neurons. Our current experiments indicate that MsContactin represents an authentic ligand for APPL that can activate this pathway (Fig. 10A). Specifically, we found that MsContactin is selectively expressed by the enteric glia while the neurons that they ensheath express APPL, and that the onset of MsContactin expression coincides with key phases of EP cell migration and outgrowth (Figs. 3-45). Using antisense constructs and fusion proteins targeting APPL and MsContactin, we also demonstrated that MsContactin binds to the EP cells in an APPL-dependent manner, whereas APPL binding to the glial cells (but not the neurons) is MsContactin-dependent (Fig. 7). Third, using our embryo culture assays, we showed that reducing the expression of either MsContactin (Fig. 6) or APPL (Fig. 8) resulted in the same distinctive pattern of ectopic migration caused by inhibiting Go $\alpha$ (Fig. 9), whereas treating the EP cells with MsCont-Fc inhibited 
their motile behavior in an APPLdependent and Go $\alpha$-dependent manner (Figs. 8, 9). In contrast, we did not detect any overt defects in glial morphology when we treated embryos with MsCon$\mathrm{t}-\mathrm{Fc}$ (data not shown), suggesting that the effects of MsCont-Fc on neuronal migration were not secondary to disrupted glial cell ensheathment.

In terms of normal development, APPL levels are substantially reduced by the time that the EP cells extend terminal branches onto the interband musculature (by $85-90$ hpf; Fig. 5C), which is also consistent with our model. Because our cultured embryos do not survive as larvae, we were unable to assess how aberrant migration and outgrowth affects gut physiology. However, given recent evidence that the insect ENS regulates reproductive and molting behaviors as well as digestion (Ayali, 2009; Schoofs et al., 2009; Cognigni et al., 2011), we think it likely that the developmental defects caused by disrupting MsContactin-APPL signaling would have a significant impact on postnatal viability.

Of note is that the inhibitory responses induced by MsCont-Fc were only partially overcome by pretreatment with APPL MOs (Fig. 8), which may reflect residual levels of APPL in these preparations (Fig. $7 J$ ). Likewise, even though knocking down glial MsContactin expression caused a significant increase in ectopic migration, only $\sim 20 \%$ of the neurons were affected in most preparations, suggesting that additional guidance cues help maintain their normal trajectories. In previous work, we showed that homophilic interactions between TM-Fas II on the neurons and the muscle bands promote EP cell guidance along these pathways, whereas GPI-Fas II regulates glial spreading (Wright and Copenhaver, 2000). For neurons that are closely aligned with a band (Fig. 10B, cell \#1), we postulate that adhesive interactions mediated by TM-Fas II (and possibly other band-specific cues) are sufficient to maintain migration and outgrowth along these preferred pathways. By comparison, when neurons extend processes off their band pathways (Fig. 10B, cell \#2), interactions between neuronal APPL and glial MsContactin induce Go $\alpha$ dependent retraction responses, thereby preventing inappropriate growth onto the interband regions. In support of this model, we found that treatment with MsCont-Fc caused a global inhibition of migration (Figs. 8, 9), consistent with hyperstimulating this response, whereas knocking down MsContactin permitted ectopic migration and outgrowth (Fig. 10C, cell \#2). Whether additional factors also regulate APPL-dependent responses in the developing ENS remains to be explored. Nevertheless, our data support the hypothesis that MsContactin functions as a physiological activator of APPL-Go $\alpha$ signaling (Fig. 10A), maintaining the neurons on their pathways by inducing APPL-dependent retraction responses away from inappropriate domains.

\section{Contactins and the control of APP-dependent responses in the developing nervous system}

Although APP may interact with a spectrum of membraneassociated and extracellular proteins (Ho and Südhof, 2004; Hoe et al., 2006, 2009; Rice et al., 2012, 2013), a growing number of studies have shown that APP and its orthologs can directly bind Contactin family proteins in different contexts (Bai et al., 2008; Ma et al., 2008; Osterfield et al., 2008; Osterhout et al., 2015; Puzzo et al., 2015). In particular, Contactins have been implicated in modulating APP-dependent aspects of retinotectal development, albeit via mechanisms that are unexpectedly complex. Based on an initial screen for proteins in the embryonic chick brain that interact with APP family proteins, Osterfield and colleagues showed that both Contactin- 3 and Contactin- 4 could directly bind APP, and that all three proteins are coexpressed in retinal ganglion cells (RGCs). They also showed that soluble sAPP fragments promoted RGC outgrowth on substrates coated with neural cell adhesion molecule by binding to neuronally expressed Contactin-4 (Osterfield et al., 2008). More recently, Osterhout and colleagues showed that both APP and Contactin-4 are required for specific subsets of RGCs to correctly innervate the accessory optic system (Osterhout et al., 2015). Since APP is expressed both by the RGCs and their targets, these studies suggest that Contactin-4 might function either as a ligand or coreceptor for APP.

However, APLP1 and APLP2 are also strongly expressed in the developing retina (Smit-McBride et al., 2011; Tkatchenko et al., 2015), both of which may interact with a variety of Contactins (Osterfield et al., 2008; Shimoda and Watanabe, 2009). More generally, given that multiple members of the APP and Contactin families are often coexpressed by neurons and glial cells and can interact both in cis and trans (Soba et al., 2005; Shimoda and Watanabe, 2009; Kaden et al., 2012; Mohebiany et al., 2014), deciphering the role of particular combinations of these proteins in the developing brain is likely to remain challenging. By comparison, the developing ENS of Manduca provides a much simpler example of this process, whereby glial MsContactin and 
neuronal APPL are expressed in a complementary manner. Our results are consistent with the expression pattern of dContactin in Drosophila, which has been detected in epithelial and glial cells (Faivre-Sarrailh et al., 2004; Banerjee et al., 2006), while APPL is only expressed in neurons (Luo et al., 1990; Torroja et al., 1996). Together, our results support the concept that Contactin-APP signaling represents an evolutionarily conserved mechanism for regulating neuronal guidance and remodeling in the nervous system.

\section{Contactin-APP signaling in both development and disease}

In addition to being widely coexpressed with APP family proteins (Hosoya et al., 1995; Virgintino et al., 1999; Zuko et al., 2011; Mohebiany et al., 2014), Contactins have been associated with many of the same developmental functions attributed to APP, including axonal guidance (Baeriswyl and Stoeckli, 2008; Osterhout et al., 2015), neurite branching (Mercati et al., 2013), synaptic formation (Sakurai et al., 2009), and neuronal-glial interactions (Bhat et al., 2001; Boyle et al., 2001; Bhat, 2003). Several Contactins have also been implicated in the control of neuronal migration, although this function may be partially due to their effects on neuronal proliferation and differentiation (Denaxa et al., 2005; Ma et al., 2008; Wang et al., 2011; Xenaki et al., 2011). Similarly, both APP and Contactins have been linked with a variety of neurodevelopmental and age-related disorders: genetic mutations affecting Contactin-3, Contactin-4, Contactin-5, and Contactin- 6 are strongly associated with autism spectrum disorders (ASDs; Zuko et al., 2013; Mohebiany et al., 2014; Nava et al., 2014; Hu et al., 2015), while elevated sAPP levels have been identified as potential biomarkers for the most severe forms of ASD (Sokol et al., 2006; Ray et al., 2011).

Postnatally, the expression of Contactins and APP family proteins undergo complex changes over the course of aging (Shimazaki et al., 1998; Kögel et al., 2012; Puzzo et al., 2015) and in response to injury (Soares et al., 2005; Chen and Tang, 2006; Corrigan et al., 2011), suggesting that APP-Contactin interactions continue to play important roles in synaptic remodeling and neuronal maintenance. A potential link between ContactinAPP signaling and AD has also been raised by the identification of a polymorphism in the human genome that is associated with late-onset Alzheimer's disease (at 3p26.2-3), which maps closely to the genes encoding Contactin-4 and Contactin-6 (Blacker et al., 2003). Based on our evidence that hyperactivation of MsContactin-APPL signaling induces neuronal stalling and retraction events in the developing nervous system, we postulate that misregulation of this pathway in the adult brain could also provoke neuronal dysfunction and synaptic loss via hyperactivation of Go $\alpha$ and its effectors (Fig. 10A), thereby contributing to the progressive pathologies that typify $\mathrm{AD}$. Determining the downstream mechanisms by which Contactin-APP signaling regulates neuronal behavior would therefore provide new insight into how the perturbation of this pathway might lead to neurodegenerative responses in the aging or injured brain.

\section{References}

Ayali A (2009) The role of the arthropod stomatogastric nervous system in moulting behaviour and ecdysis. J Exp Biol 212:453-459. CrossRef Medline

Baeriswyl T, Stoeckli ET (2008) Axonin-1/TAG-1 is required for pathfinding of granule cell axons in the developing cerebellum. Neural Dev 3:7.2322981. CrossRef Medline

Bai Y, Markham K, Chen F, Weerasekera R, Watts J, Horne P, Wakutani Y, Bagshaw R, Mathews PM, Fraser PE, Westaway D, St George-Hyslop P,
Schmitt-Ulms G (2008) The in vivo brain interactome of the amyloid precursor protein. Mol Cell Proteomics 7:15-34. Medline

Banerjee S, Pillai AM, Paik R, Li J, Bhat MA (2006) Axonal ensheathment and septate junction formation in the peripheral nervous system of Drosophila. J Neurosci 26:3319-3329. CrossRef Medline

Banker G, Goslin K (1998) Culturing nerve cells. Cambridge, MA: MIT.

Bhat MA (2003) Molecular organization of axo-glial junctions. Curr Opin Neurobiol 13:552-559. CrossRef Medline

Bhat MA, Rios JC, Lu Y, Garcia-Fresco GP, Ching W, St Martin M, Li J, Einheber S, Chesler M, Rosenbluth J, Salzer JL, Bellen HJ (2001) Axonglia interactions and the domain organization of myelinated axons requires neurexin IV/Caspr/Paranodin. Neuron 30:369-383. CrossRef Medline

Blacker D, Bertram L, Saunders AJ, Moscarillo TJ, Albert MS, Wiener H, Perry RT, Collins JS, Harrell LE, Go RC, Mahoney A, Beaty T, Fallin MD, Avramopoulos D, Chase GA, Folstein MF, McInnis MG, Bassett SS, Doheny KJ, Pugh EW et al. (2003) Results of a high-resolution genome screen of 437 Alzheimer's disease families. Hum Mol Genet 12:23-32. CrossRef Medline

Boyle ME, Berglund EO, Murai KK, Weber L, Peles E, Ranscht B (2001) Contactin orchestrates assembly of the septate-like junctions at the paranode in myelinated peripheral nerve. Neuron 30:385-397. CrossRef Medline

Brouillet E, Trembleau A, Galanaud D, Volovitch M, Bouillot C, Valenza C, Prochiantz A, Allinquant B (1999) The amyloid precursor protein interacts with Go heterotrimeric protein within a cell compartment specialized in signal transduction. J Neurosci 19:1717-1727. Medline

Carson JH, Gao Y, Tatavarty V, Levin MK, Korza G, Francone VP, Kosturko LD, Maggipinto MJ, Barbarese E (2008) Multiplexed RNA trafficking in oligodendrocytes and neurons. Biochim Biophys Acta 1779:453-458. CrossRef Medline

Chen Y, Tang BL (2006) The amyloid precursor protein and postnatal neurogenesis/neuroregeneration. Biochem Biophys Res Commun 341:1-5. CrossRef Medline

Coate TM, Swanson TL, Proctor TM, Nighorn AJ, Copenhaver PF (2007) Eph receptor expression defines midline boundaries for ephrin-positive migratory neurons in the enteric nervous system of Manduca sexta. J Comp Neurol 502:175-191. Medline

Coate TM, Wirz JA, Copenhaver PF (2008) Reverse signaling via a glycosylphosphatidylinositol-linked ephrin prevents midline crossing by migratory neurons during embryonic development in Manduca. J Neurosci 28:3846-3860. CrossRef Medline

Cognigni P, Bailey AP, Miguel-Aliaga I (2011) Enteric neurons and systemic signals couple nutritional and reproductive status with intestinal homeostasis. Cell Metab 13:92-104. CrossRef Medline

Copenhaver PF (1993) Origins, migration, and differentiation of glial cells in the insect nervous system from a discrete set of glial precursors. Development 117:59-74.

Copenhaver PF (2007) How to innervate a simple gut: familiar themes and unique aspects in the formation of the insect enteric nervous system. Dev Dyn 236:1841-1864. Medline

Copenhaver PF, Taghert PH (1989a) Development of the enteric nervous system in the moth I. Diversity of cell types and the embryonic expression of FMRFamide-related neuropeptides. Dev Biol 131:70-84. Medline

Copenhaver PF, Taghert PH (1989b) Development of the enteric nervous system in the moth II. Stereotyped cell migration precedes the differentiation of embryonic neurons. Dev Biol 131:85-101. CrossRef Medline

Copenhaver PF, Taghert PH (1990) Neurogenesis in the insect enteric nervous system: generation of pre-migratory neurons from an epithelial placode. Development 109:17-28. Medline

Copenhaver PF, Taghert PH (1991) Origins of the insect enteric nervous system: differentiation of the enteric ganglia from a neurogenic epithelium. Development 113:1115-1132. Medline

Corrigan F, Pham CL, Vink R, Blumbergs PC, Masters CL, van den Heuvel C, Cappai R (2011) The neuroprotective domains of the amyloid precursor protein, in traumatic brain injury, are located in the two growth factor domains. Brain Res 1378:137-143. CrossRef Medline

Dawkins E, Small DH (2014) Insights into the physiological function of the beta-amyloid precursor protein: beyond Alzheimer's disease. J Neurochem 129:756-769.4314671. CrossRef Medline

Denaxa M, Kyriakopoulou K, Theodorakis K, Trichas G, Vidaki M, Takeda Y, Watanabe K, Karagogeos D (2005) The adhesion molecule TAG-1 is 
required for proper migration of the superficial migratory stream in the medulla but not of cortical interneurons. Dev Biol 288:87-99. CrossRef Medline

Deyts C, Thinakaran G, Parent AT (2016) APP Receptor? To be or not to be. Trends Pharmacol Sci 37:390-411. CrossRef Medline

Faivre-Sarrailh C, Banerjee S, Li J, Hortsch M, Laval M, Bhat MA (2004) Drosophila contactin, a homolog of vertebrate contactin, is required for septate junction organization and paracellular barrier function. Development 131:4931-4942. CrossRef Medline

Flanagan JG, Cheng HJ (2000) Alkaline phosphatase fusion proteins for molecular characterization and cloning of receptors and their ligands. Methods Enzymol 327:198-210. CrossRef Medline

Forloni G, Demicheli F, Giorgi S, Bendotti C, Angeretti N (1992) Expression of amyloid precursor protein mRNAs in endothelial, neuronal and glial cells: modulation by interleukin-1. Brain Res Mol Brain Res 16:128-134. CrossRef Medline

Freigang J, Proba K, Leder L, Diederichs K, Sonderegger P, Welte W (2000) The crystal structure of the ligand binding module of axonin-1/TAG-1 suggests a zipper mechanism for neural cell adhesion. Cell 101:425-433. CrossRef Medline

Ganot P, Zoccola D, Tambutté E, Voolstra CR, Aranda M, Allemand D, Tambutté S (2015) Structural molecular components of septate junctions in cnidarians point to the origin of epithelial junctions in eukaryotes. Mol Biol Evol 32:44-62. CrossRef Medline

Heber S, Herms J, Gajic V, Hainfellner J, Aguzzi A, Rülicke T, von Kretzschmar H, von Koch C, Sisodia S, Tremml P, Lipp HP, Wolfer DP, Müller U (2000) Mice with combined gene knock-outs reveal essential and partially redundant functions of amyloid precursor protein family members. J Neurosci 20:7951-7963. Medline

Herms J, Anliker B, Heber S, Ring S, Fuhrmann M, Kretzschmar H, Sisodia S, Müller U (2004) Cortical dysplasia resembling human type 2 lissencephaly in mice lacking all three APP family members. EMBO J 23:41064115. CrossRef Medline

Ho A, Südhof TC (2004) Binding of F-spondin to amyloid-beta precursor protein: a candidate amyloid-beta precursor protein ligand that modulates amyloid-beta precursor protein cleavage. Proc Natl Acad Sci U S A 101:2548-2553. CrossRef Medline

Hoe HS, Tran TS, Matsuoka Y, Howell BW, Rebeck GW (2006) DAB1 and Reelin effects on amyloid precursor protein and ApoE receptor 2 trafficking and processing. J Biol Chem 281:35176-35185. CrossRef Medline

Hoe HS, Lee KJ, Carney RS, Lee J, Markova A, Lee JY, Howell BW, Hyman BT, Pak DT, Bu G, Rebeck GW (2009) Interaction of reelin with amyloid precursor protein promotes neurite outgrowth. J Neurosci 29:74597473. CrossRef Medline

Horgan AM, Copenhaver PF (1998) G-protein-mediated inhibition of neuronal migration requires calcium influx. J Neurosci 18:4189-4200. Medline

Horgan AM, Lagrange MT, Copenhaver PF (1995) A developmental role for the heterotrimeric $\mathrm{G}$ protein Go alpha in a migratory population of embryonic neurons. Dev Biol 172:640-653. Medline

Hosoya H, Shimazaki K, Kobayashi S, Takahashi H, Shirasawa T, Takenawa T, Watanabe K (1995) Developmental expression of the neural adhesion molecule F3 in the rat brain. Neurosci Lett 186:83-86. Medline

Hu J, Liao J, Sathanoori M, Kochmar S, Sebastian J, Yatsenko SA, Surti U (2015) CNTN6 copy number variations in 14 patients: a possible candidate gene for neurodevelopmental and neuropsychiatric disorders. J Neurodev Disord 7:26. CrossRef Medline

Kaden D, Munter LM, Reif B, Multhaup G (2012) The amyloid precursor protein and its homologues: structural and functional aspects of native and pathogenic oligomerization. Eur J Cell Biol 91:234-239. CrossRef Medline

Katidou M, Tavernarakis N, Karagogeos D (2013) The contactin RIG-6 mediates neuronal and non-neuronal cell migration in Caenorhabditis elegans. Dev Biol 373:184-195. CrossRef Medline

Kögel D, Deller T, Behl C (2012) Roles of amyloid precursor protein family members in neuroprotection, stress signaling and aging. Exp Brain Res 217:471-479. CrossRef Medline

Lourenço FC, Galvan V, Fombonne J, Corset V, Llambi F, Müller U, Bredesen DE, Mehlen P (2009) Netrin-1 interacts with amyloid precursor protein and regulates amyloid-beta production. Cell Death Differ 16:655-663. CrossRef Medline

Luo LQ, Martin-Morris LE, White K (1990) Identification, secretion, and neural expression of APPL, a Drosophila protein similar to human amyloid protein precursor. J Neurosci 10:3849-3861. Medline

Luo L, Tully T, White K (1992) Human amyloid precursor protein ameliorates behavioral deficit of flies deleted for Appl gene. Neuron 9:595-605. CrossRef Medline

Ma QH, Futagawa T, Yang WL, Jiang XD, Zeng L, Takeda Y, Xu RX, Bagnard D, Schachner M, Furley AJ, Karagogeos D, Watanabe K, Dawe GS, Xiao ZC (2008) A TAG1-APP signalling pathway through Fe65 negatively modulates neurogenesis. Nat Cell Biol 10:283-294. CrossRef Medline

Mercati O, Danckaert A, André-Leroux G, Bellinzoni M, Gouder L, Watanabe K, Shimoda Y, Grailhe R, De Chaumont F, Bourgeron T, Cloëz-Tayarani I (2013) Contactin 4, -5 and -6 differentially regulate neuritogenesis while they display identical PTPRG binding sites. Biol Open 2:324-334. CrossRef Medline

Mohebiany AN, Harroch S, Bouyain S (2014) New insights into the roles of the contactin cell adhesion molecules in neural development. Adv Neurobiol 8:165-194. Medline

Mörtl M, Sonderegger P, Diederichs K, Welte W (2007) The crystal structure of the ligand-binding module of human TAG-1 suggests a new mode of homophilic interaction. Protein Sci 16:2174-2183. Medline

Nava C, Keren B, Mignot C, Rastetter A, Chantot-Bastaraud S, Faudet A, Fonteneau E, Amiet C, Laurent C, Jacquette A, Whalen S, Afenjar A, Perisse D, Doummar D, Dorison N, Leboyer M, Siffroi JP, Cohen D, Brice A, Héron D et al. (2014) Prospective diagnostic analysis of copy number variants using SNP microarrays in individuals with autism spectrum disorders. Eur J Hum Genet 22:71-78. CrossRef Medline

O’Brien RJ, Wong PC (2011) Amyloid precursor protein processing and Alzheimer's disease. Annu Rev Neurosci 34:185-204. CrossRef Medline

Okamoto T, Takeda S, Murayama Y, Ogata E, Nishimoto I (1995) Liganddependent $\mathrm{G}$ protein coupling function of amyloid transmembrane precursor. J Biol Chem 270:4205-4208. Medline

Osterfield M, Egelund R, Young LM, Flanagan JG (2008) Interaction of amyloid precursor protein with contactins and NgCAM in the retinotectal system. Development 135:1189-1199. CrossRef Medline

Osterhout JA, Stafford BK, Nguyen PL, Yoshihara Y, Huberman AD (2015) Contactin-4 mediates axon-target specificity and functional development of the accessory optic system. Neuron 86:985-999. CrossRef Medline

Patel NH, Goodman CS (1992) DIG-labeled single-stranded DNA probes for in situ hybridization. In: Non-radioactive labelling and detection of biomolecules (Kessler C, ed), pp 377-381. Heidelberg: Springer.

Puzzo D, Bizzoca A, Loreto C, Guida CA, Gulisano W, Frasca G, Bellomo M, Castorina S, Gennarini G, Palmeri A (2015) Role of F3/contactin expression profile in synaptic plasticity and memory in aged mice. Neurobiol Aging 36:1702-1715. CrossRef Medline

Quraishe S, Wyttenbach A, Matinyarare N, Perry VH, Fern R, O'Connor V (2016) Selective and compartmentalized myelin expression of HspB5. Neuroscience 316:130-142. CrossRef Medline

Ramaker JM, Swanson TL, Copenhaver PF (2013) Amyloid precursor proteins interact with the heterotrimeric G-protein Go in the control of neuronal migration. J Neurosci 33:10165-10181. CrossRef Medline

Ray B, Long JM, Sokol DK, Lahiri DK (2011) Increased secreted amyloid precursor protein-alpha (sAPPalpha) in severe autism: proposal of a specific, anabolic pathway and putative biomarker. PLoS One 6:e20405.3120811. CrossRef Medline

Rice HC, Townsend M, Bai J, Suth S, Cavanaugh W, Selkoe DJ, Young-Pearse TL (2012) Pancortins interact with amyloid precursor protein and modulate cortical cell migration. Development 139:3986-3996. CrossRef Medline

Rice HC, Young-Pearse TL, Selkoe DJ (2013) Systematic evaluation of candidate ligands regulating ectodomain shedding of amyloid precursor protein. Biochemistry 52:3264-3277. CrossRef Medline

Robinow S, White K (1991) Characterization and spatial distribution of the ELAV protein during Drosophila melanogaster development. J Neurobiol 22:443-461. CrossRef Medline

Sakurai K, Toyoshima M, Ueda H, Matsubara K, Takeda Y, Karagogeos D, Shimoda Y, Watanabe K (2009) Contribution of the neural cell recognition molecule NB-3 to synapse formation between parallel fibers and Purkinje cells in mouse. Dev Neurobiol 69:811-824. CrossRef Medline

Schindelin J, Arganda-Carreras I, Frise E, Kaynig V, Longair M, Pietzsch T, Preibisch S, Rueden C, Saalfeld S, Schmid B, Tinevez JY, White DJ, Hartenstein V, Eliceiri K, Tomancak P, Cardona A (2012) Fiji: an open- 
source platform for biological-image analysis. Nat Methods 9:676-682. CrossRef Medline

Schoofs A, Niederegger S, Spiess R (2009) From behavior to fictive feeding: anatomy, innervation and activation pattern of pharyngeal muscles of Calliphora vicina 3rd instar larvae. J Insect Physiol 55:218-230. CrossRef Medline

Shimazaki K, Hosoya H, Takeda Y, Kobayashi S, Watanabe K (1998) Agerelated decline of F3/contactin in rat hippocampus. Neurosci Lett 245: 117-120. CrossRef Medline

Shimoda Y, Watanabe K (2009) Contactins: emerging key roles in the development and function of the nervous system. Cell Adh Migr 3:64-70. Medline

Shimoda Y, Koseki F, Itoh M, Toyoshima M, Watanabe K (2012) A ciscomplex of NB-2/contactin-5 with amyloid precursor-like protein 1 is localized on the presynaptic membrane. Neurosci Lett 510:148-153. CrossRef Medline

Smith R (2004) Moving molecules: mRNA trafficking in mammalian oligodendrocytes and neurons. Neuroscientist 10:495-500. CrossRef Medline

Smit-McBride Z, Modjtahedi SP, Cessna CT, Telander DG, Hjelmeland LM, Morse LS (2011) In vivo gene expression profiling of retina postintravitreal injections of dexamethasone and triamcinolone at clinically relevant time points for patient care. Invest Ophthalmol Vis Sci 52:8965-8978. CrossRef Medline

Soares S, Traka M, von Boxberg Y, Bouquet C, Karagogeos D, Nothias F (2005) Neuronal and glial expression of the adhesion molecule TAG-1 is regulated after peripheral nerve lesion or central neurodegeneration of adult nervous system. Eur J Neurosci 21:1169-1180. Medline

Soba P, Eggert S, Wagner K, Zentgraf H, Siehl K, Kreger S, Löwer A, Langer A, Merdes G, Paro R, Masters CL, Müller U, Kins S, Beyreuther K (2005) Homo- and heterodimerization of APP family members promotes intercellular adhesion. EMBO J 24:3624-3634. Medline

Sokol DK, Chen D, Farlow MR, Dunn DW, Maloney B, Zimmer JA, Lahiri DK (2006) High levels of Alzheimer beta-amyloid precursor protein (APP) in children with severely autistic behavior and aggression. J Child Neurol 21:444-449. Medline

Swanson TL, Knittel LM, Coate TM, Farley SM, Snyder MA, Copenhaver PF (2005) The insect homologue of the amyloid precursor protein interacts with the heterotrimeric $G$ protein Go alpha in an identified population of migratory neurons. Dev Biol 288:160-178. Medline

Tachi N, Hashimoto Y, Nawa M, Matsuoka M (2010) TAG-1 is an inhibitor of TGFbeta2-induced neuronal death via amyloid beta precursor protein. Biochem Biophys Res Commun 394:119-125. Medline

Thambi NC, Quan F, Wolfgang WJ, Spiegel A, Forte M (1989) Immunological and molecular characterization of Go(alpha)-like proteins in the Drosophila CNS. J Biol Chem 264:18552-18560. Medline
Tkatchenko AV, Tkatchenko TV, Guggenheim JA, Verhoeven VJ, Hysi PG, Wojciechowski R, Singh PK, Kumar A, Thinakaran G, Thinakaran G, Williams C (2015) APLP2 regulates refractive error and myopia development in mice and humans. PLoS Genet 11:e1005432. CrossRef Medline

Torroja L, Luo L, White K (1996) APPL, the Drosophila member of the APP-family, exhibits differential trafficking and processing in CNS neurons. J Neurosci 16:4638-4650. Medline

van der Kant R, Goldstein LS (2015) Cellular functions of the amyloid precursor protein from development to dementia. Dev Cell 32:502-515. CrossRef Medline

Virgintino D, Ambrosini M, D’Errico P, Bertossi M, Papadaki C, Karagogeos D, Gennarini G (1999) Regional distribution and cell type-specific expression of the mouse F3 axonal glycoprotein: a developmental study. J Comp Neurol 413:357-372. Medline

Wang W, Karagogeos D, Kilpatrick DL (2011) The effects of Tag-1 on the maturation of mouse cerebellar granule neurons. Cell Mol Neurobiol 31:351-356. CrossRef Medline

Wright JW, Copenhaver PF (2000) Different isoforms of fasciclin II play distinct roles in the guidance of neuronal migration during insect embryogenesis. Dev Biol 225:59-78. Medline

Wright JW, Copenhaver PF (2001) Cell type-specific expression of fasciclin II isoforms reveals neuronal-glial interactions during peripheral nerve growth. Dev Biol 234:24-41. Medline

Wright JW, Snyder MA, Schwinof KM, Combes S, Copenhaver PF (1999) A role for fasciclin II in the guidance of neuronal migration. Development 126:3217-3228. Medline

Xenaki D, Martin IB, Yoshida L, Ohyama K, Gennarini G, Grumet M, Sakurai T, Furley AJ (2011) F3/contactin and TAG1 play antagonistic roles in the regulation of sonic hedgehog-induced cerebellar granule neuron progenitor proliferation. Development 138:519-529. CrossRef Medline

Yoshihara Y, Kawasaki M, Tamada A, Nagata S, Kagamiyama H, Mori K (1995) Overlapping and differential expression of BIG-2, BIG-1, TAG-1, and F3: four members of an axon-associated cell adhesion molecule subgroup of the immunoglobulin superfamily. J Neurobiol 28:51-69. CrossRef Medline

Zheng H, Koo EH (2011) Biology and pathophysiology of the amyloid precursor protein. Mol Neurodegener 6:27. CrossRef Medline

Zuko A, Bouyain S, van der Zwaag B, Burbach JP (2011) Contactins: structural aspects in relation to developmental functions in brain disease. Adv Protein Chem Struct Biol 84:143-180. CrossRef Medline

Zuko A, Kleijer KT, Oguro-Ando A, Kas MJ, van Daalen E, van der Zwaag B, Burbach JP (2013) Contactins in the neurobiology of autism. Eur J Pharmacol 719:63-74. CrossRef Medline 